
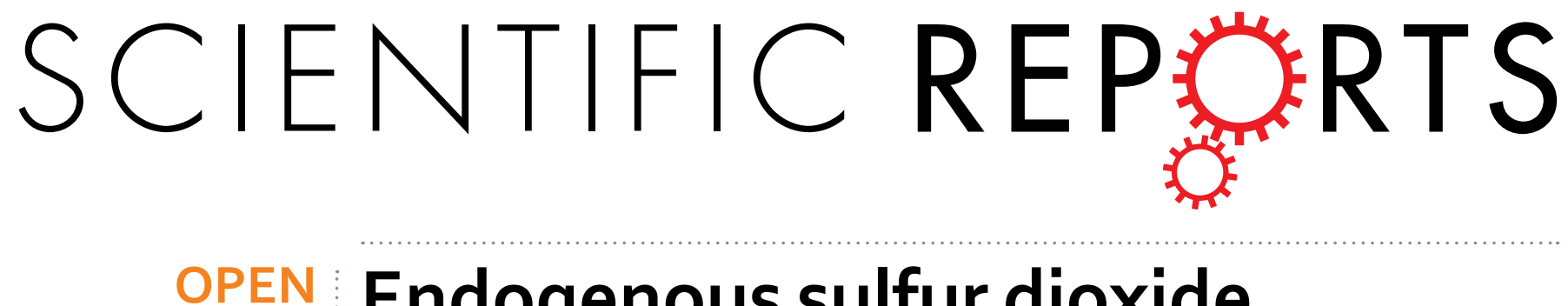

Received: 09 September 2015

Accepted: 09 December 2015

Published: 14 January 2016

\title{
Endogenous sulfur dioxide alleviates collagen remodeling via inhibiting TGF- $\beta /$ Smad pathway in vascular smooth muscle cells
}

Yaqian Huang ${ }^{1}$, Zhizhou Shen ${ }^{1}$, Qinghua Chen ${ }^{1}$, Pan Huang ${ }^{1}$, Heng Zhang ${ }^{2}$, Shuxu Du ${ }^{3}$, Bin Geng ${ }^{4}$, Chunyu Zhang ${ }^{1}$, Kun $\mathrm{Li}^{5}$, Chaoshu Tang ${ }^{4,6}$, Junbao Du ${ }^{1,6}$ \& Hongfang Jin ${ }^{1}$

The study was designed to investigate the role of endogenous sulfur dioxide $\left(\mathrm{SO}_{2}\right)$ in collagen remodeling and its mechanisms in vascular smooth muscle cells (VSMCs). Overexpression of endogenous $\mathrm{SO}_{2}$ synthase aspartate aminotransferase (AAT) 1 or 2 increased $\mathrm{SO}_{2}$ levels and inhibited collagen I and III expressions induced by transforming growth factor (TGF)- $\beta 1$ in VSMCs. In contrast, AAT1 or AAT2 knockdown induced a severe collagen deposition in TGF- $\beta 1$-treated VSMCs. Furthermore, AAT1 or AAT2 overexpression suppressed procollagen I and III mRNA, upregulated matrix metalloproteinase (MMP)-13 expression, downregulated tissue inhibitors of MMP-1 level, and vice versa. Mechanistically, AAT1 or AAT2 overexpression inhibited phosphorylation of type ITGF- $\beta$ receptor (T $\beta R I$ ) and Smad2/3 in TGF-31-stimulated VSMCs. Whereas SB431542, an inhibitor of TGF- $\beta 1 /$ Smad signaling pathway, attenuated excessive collagen deposition induced by AAT knockdown. Most importantly, ectopically expressing AAT or exogenous addition of $100 \mu \mathrm{M} \mathrm{SO}_{2}$ blocked AAT deficiencyaggravated collagen accumulation in TGF- $\beta 1$-stimulatd VSMCs, while no inhibition was observed at $100 \mu \mathrm{M}$ ethyl pyruvate. These findings indicated that endogenous $\mathrm{SO}_{2}$ alleviated collagen remodeling

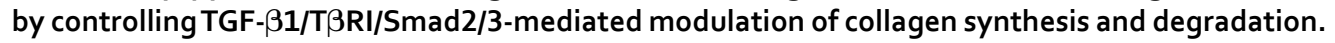

Severe structural changes in vascular walls characterized by vascular collagen remodeling are central to the pathophysiology of vascular diseases such as hypertension, atherosclerosis and restenosis after coronary angioplasty ${ }^{1,2}$. Vascular collagen mainly consists of collagen I and III. Collagen I is associated with the tenacity and tensile strength of vascular wall, while collagen III is associated with the elasticity of vascular wall, both play important role in maintaining the integrity of vascular structure. Previous study indicated that vascular collagen remodeling was the consequence of an imbalance between collagen synthesis and degradation, characterized by excessive deposition of collagen, disequilibrium of collagen types (increased ratio of collagen I/III) and disorganized collagen arrangement ${ }^{3}$. Among them, the excessive deposition of collagen I and III in vascular wall is one of the most important factors of vascular remodeling, and is also a common consequence of many cardiovascular diseases. The synthesis and degradation of collagen in VSMC are critical to vascular remodeling ${ }^{3,4}$, but much less is known about the pathogenetic mechanism of collagen remodeling in VSMC under pathological conditions, especially the regulatory mechanism of abnormal synthesis and (or) degradation of collagen has not been fully elucidated.

More and more research has suggested that endogenous gaseous signaling molecules play important function in cardiovascular system. It was reported that the gasotransmitter hydrogen sulfide inhibited the abnormal accumulation of vascular collagen, and alleviated vascular remodeling in spontaneously hypertensive rats ${ }^{5,6}$. Sulfur dioxide $\left(\mathrm{SO}_{2}\right)$, another gasotransmitter, shares the same substrate with hydrogen sulfide, which also can

${ }^{1}$ Department of Pediatrics, Peking University First Hospital, Beijing 100034, P. R. China. ${ }^{2}$ Department of Endocrinology, Beijing Chao-Yang Hospital, Capital Medical University, Beijing 100020, P. R. China. ${ }^{3}$ Department of Pediatrics, Capital Medical University Shijitan Hospital, Beijing 100038, P. R. China. ${ }^{4}$ Department of Physiology and Pathophysiology, Peking University Health Science Centre, Beijing 100191, P. R. China. ${ }^{5}$ Key Laboratory of Green Chemistry and Technology, Ministry of Education, College of Chemistry, Sichuan University, Chengdu, 610064, P. R. China. ${ }^{6}$ Key Laboratory of Molecular Cardiology, Ministry of Education, Beijing 100191, P. R. China. Correspondence and requests for materials should be addressed to J.D. (email: junbaodu1@126.com) or H.J. (email: jinhongfang51@126.com) 
be endogenously generated from a sulfur-containing amino $\mathrm{acid}^{7}$. L-cysteine can be oxidized by cysteine dioxygenase to L-cysteine sulfinate, which can be transformed into $\beta$-sulfinylpyruvate by aspartate aminotransferase (AAT), and then spontaneously decomposes to pyruvate and $\mathrm{SO}_{2}{ }^{8}$. Study has shown that $\mathrm{SO}_{2}$ could inhibit hypoxic pulmonary vascular remodeling ${ }^{9}$. However, it's still unclear about the regulation of endogenous $\mathrm{SO}_{2}$ on the collagen remodeling in VSMCs, and its possible mechanism.

Transforming growth factor- $\beta 1$ (TGF- $\beta 1$ ) is widely known as a key factor in vascular collagen remodeling, participating in the development of vascular injury in a variety of cardiovascular diseases. There are three isoforms of TGF- $\beta$, TGF- $\beta 1$, TGF- $\beta 2$ and TGF- $\beta 3$. TGF- $\beta 1$ is the major isoform of the TGF- $\beta$ superfamily, can be produced by VSMCs, and regulates growth, differentiation, migration and proliferation of VSMCs as well as extracellular matrix deposition ${ }^{10,11}$. Although TGF- $\beta 1$ action involve many downstream signaling pathways and cross-talk, the intracellular Smad signaling pathway is considered to play a crucial role in mediating the intracellular response to TGF- $\beta 1^{12}$. Activated TGF- $\beta 1$ binds tightly to transmembrane type II TGF- $\beta$ receptor (T $\beta$ RII), a serine/threonine kinase which phosphorylates type I TGF- $\beta$ receptor (T $\beta R I)$. Then the phosphorylated T $\beta$ RI triggers Smad 2 and Smad3 phosphorylation. The phosphorylated Smad2/3 forms a complex with Smad4 and translocate from cytoplasm into the nucleus and acts as a transcription factor to enhance the transcription of collagen, matrix metalloproteinases (MMPs) and tissue inhibitors of MMPs (TIMPs). TGF- $\beta 1$ directly promotes collagen synthesis and inhibits collagen degradation, thus resulting in the abnormal deposition of collagen ${ }^{13,14}$.

Based on these discoveries, we designed experiments to explore the role of endogenous $\mathrm{SO}_{2}$ in the TGF- $\beta 1$-induced collagen remodeling in VSMCs and its possible mechanisms.

\section{Results}

Endogenous sulfur dioxide was associated with the inhibition of TGF- $\beta 1$-induced collagen remodeling in VSMCs. Sulfur dioxide could be endogenously produced from L-cysteine in mammals through transamination by AAT. To investigate the effect of endogenous $\mathrm{SO}_{2}$ on collagen remodeling in VSMCs, we overexpressed two isozymes of AAT, AAT1 and AAT2 in VSMCs respectively. Transfection of VSMCs with AAT1 or AAT2 plasmid could significantly increase AAT1 or AAT2 protein expression as compared with vehicle (Fig. 1a). In accordance, the endogenous $\mathrm{SO}_{2}$ level was obviously elevated in VSMCs transfected with AAT1 or AAT2 plasmid (Fig. 1b). HPLC-FD assay also showed that much higher $\mathrm{SO}_{2}$ content in the supernatant from VSMCs transfected with AAT1 or AAT2 plasmid than vehicle (Fig. 1c). And the concentration of $\mathrm{SO}_{2}$ corrected by the number of cells was also increased significantly by AAT overexpression (Fig. 1d). Both immunofluorescence method and Western blot analysis showed that TGF- $\beta 1$ could upregulated protein expression of collagen I and III in VSMCs, while AAT1 or AAT2 overexpression could significantly inhibit the TGF- $\beta 1$-induced collagen I and III expression (Fig. 1e,f). Therefore, these results indicated that endogenous $\mathrm{SO}_{2}$ might suppress TGF- $\beta 1$-induced excessive collagen deposition in VSMCs.

Endogenous sulfur dioxide deficiency aggravated the TGF- $\beta 1$-induced collagen remodeling in VSMCs. To further investigate the potential causal role of endogenous $\mathrm{SO}_{2}$ in vascular collagen remodeling, we used shRNA to knock down AAT1 or AAT2. Specific knockdown of AAT1 or AAT2 was verified at protein level by Western blot analysis (Fig. 2a). In agreement, transfection with AAT1 shRNA or AAT2 shRNA significantly decreased endogenous $\mathrm{SO}_{2}$ in VSMCs, as well as the $\mathrm{SO}_{2}$ level in the supernatant (Fig. $2 \mathrm{~b}, \mathrm{c}$ ). As compared with control shRNA, endogenous $\mathrm{SO}_{2}$ silencing greatly exacerbated TGF- $\beta 1$-induced collagen I and III expression in VSMCs (Fig. 2d,e). These data probably supported a significant role of endogenous $\mathrm{SO}_{2}$ in the regulation of collagen remodeling in VSMCs.

Endogenous sulfur dioxide likely inhibited the TGF- $\beta 1$-induced collagen remodeling in VSMCs via suppressing collagen synthesis. Collagen synthesis is one major link in collagen expression regulation, mainly reflected in the transcription and translation of procollagen gene. Real-time quantitative PCR (RT-PCR) analysis showed that TGF- $\beta 1$ stimulation increased the mRNA levels of procollagen I and III, while AAT1 or AAT2 overexpression could significantly inhibit the TGF- $\beta 1$-induced mRNA expression of procollagen I and III (Fig. 3a,b). In contrast, AAT1 or AAT2 knockdown further exacerbated it (Fig. 3c,d). These results indicated that endogenous $\mathrm{SO}_{2}$ likely inhibited the collagen remodeling in VSMCs via inhibiting collagen synthesis.

Endogenous sulfur dioxide possibly inhibited the TGF- $\beta 1$-induced collagen remodeling in VSMCs via promoting collagen degradation. Collagen degradation is the other major link in collagen expression regulation. The key molecules regulating the collagen degradation in VSMCs are matrix metalloproteinase-13 (MMP-13) promoting collagen degradation, and tissue inhibitor of metalloproteinase-1 (TIMP-1) suppressing collagen degradation. RT-PCR and Western blot analysis showed that TGF- $\beta 1$ downregulated the MMP-13 mRNA and protein levels in VSMCs, whereas increased the TIMP-1 mRNA and protein levels (Fig. 4a-c). AAT1 or AAT2 overexpression in VSMCs could obviously elevate the TGF- $\beta 1$-downregulated MMP-13 mRNA and protein levels, and suppress the TGF- 31 -upregulated TIMP- 1 mRNA and protein levels (Fig. 4a-c). In contrast, AAT1 or AAT2 knockdown could further inhibit the TGF- $\beta 1$-downregulated mRNA and protein expressions of MMP-13, and further promote the TGF- $\beta 1$-upregulated mRNA and protein expressions of TIMP-1 (Fig. 4d-f). These results suggested that endogenous $\mathrm{SO}_{2}$ possibly inhibited the collagen remodeling in VSMCs via promoting collagen degradation.

Endogenous sulfur dioxide might inhibit the 5 mad2/3 signaling pathway during TGF- $\beta 1$-induced collagen remodeling in VSMCs. Considering TGF- $\beta / \mathrm{Smad} 2 / 3$ signal is the key pathway in regulating collagen remodeling, next we observed whether this signaling pathway was involved in the regulation of endogenous $\mathrm{SO}_{2}$ on collagen remodeling in VSMCs. Western blot analysis showed that TGF- $\beta 1$ promoted the phosphorylation of Smad2 and Smad3 as compared with control, while AAT1 or AAT2 overexpression 
a
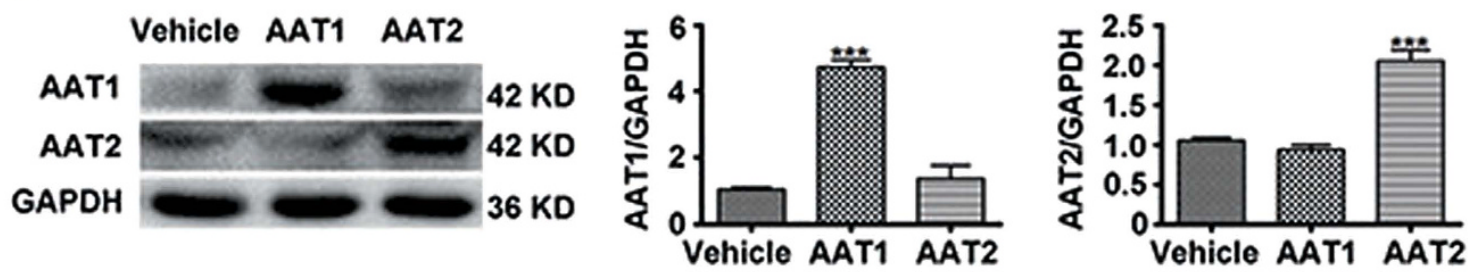

b
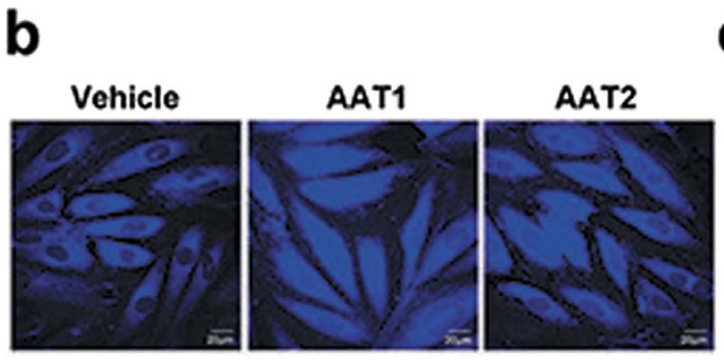

C

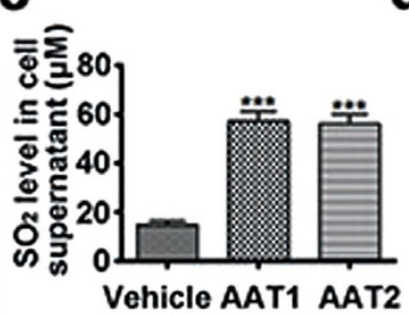

d.

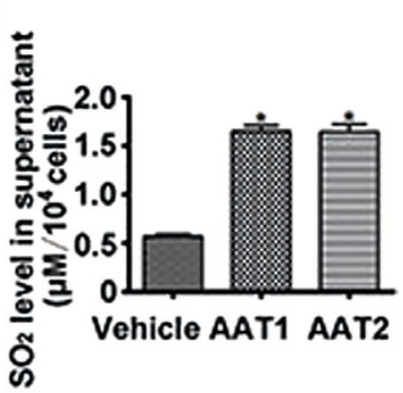

$\mathbf{e}$
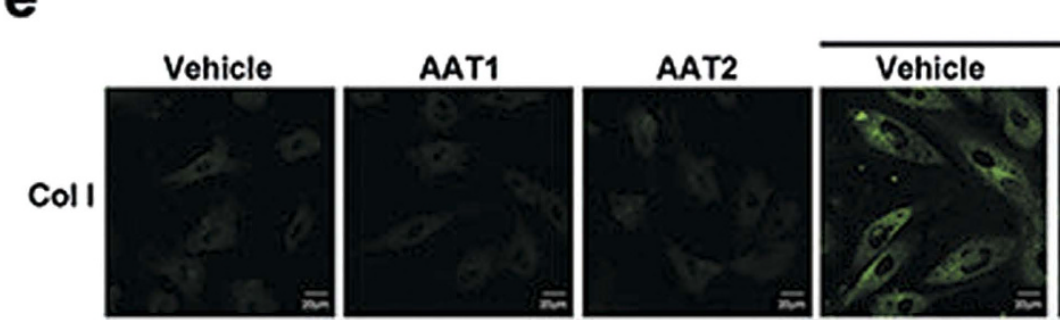

TGF- $\beta 1$
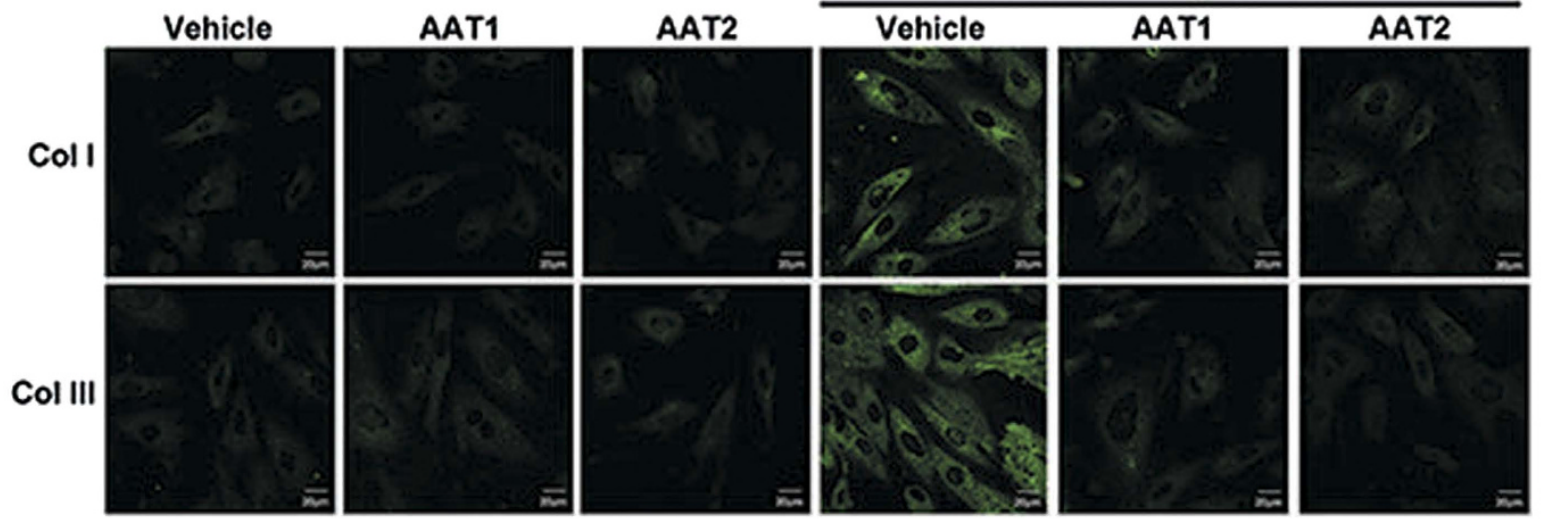

$\mathbf{f}$
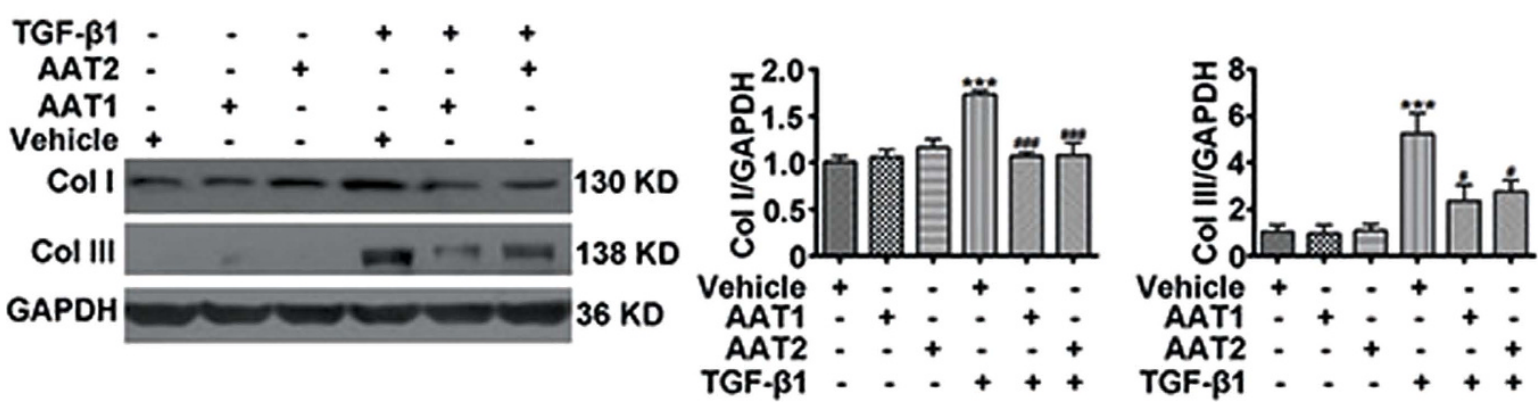

Figure 1. Endogenous $\mathrm{SO}_{2}$ overexpression inhibited TGF- $\beta 1$-induced VSMC collagen remodeling. (a) Protein expression of AAT1 and AAT2 in VSMCs transfected with $2 \mu \mathrm{g}$ of AAT1, AAT2 or vehicle plasmid for 48 h. (b) Representative fluorescent staining (blue) of endogenous $\mathrm{SO}_{2}$ in VSMCs transfected with AAT1, AAT2 or vehicle plasmid for $48 \mathrm{~h}$. Scale bar, $20 \mu \mathrm{m}$. (c) $\mathrm{SO}_{2}$ content in supernatant from VSMCs transfected with AAT1, AAT2 or vehicle plasmid for $48 \mathrm{~h}$. (d) $\mathrm{SO}_{2}$ content in supernatant from VSMCs transfected with AAT or vehicle plasmid was corrected with the number of cells $\left(\times 10^{4}\right)$. (e) Collagen I (Col I) and III (Col III) expression in VSMCs by confocal images. VSMCs in coverslips were transfected with AAT1, AAT2 or vehicle before TGF- $\beta 1$ (10 ng/ml) stimulation for $24 \mathrm{~h}$. Scale bar, $20 \mu \mathrm{m}$. (f) Representative Western blot and quantification of collagen I and III in VSMCs transfected with AAT1, AAT2 or vehicle plasmid before TGF- $\beta 1$ treatment. ${ }^{* *} P<0.001$ compared with vehicle, ${ }^{*} P<0.05$ compared with vehicle, ${ }^{\# \# \#} P<0.001$ or ${ }^{\sharp} P<0.05$ compared with vehicle + TGF- $\beta 1$ group (ANOVA). Data are represented as mean $\pm \operatorname{SD}(n=4-5)$. 
a
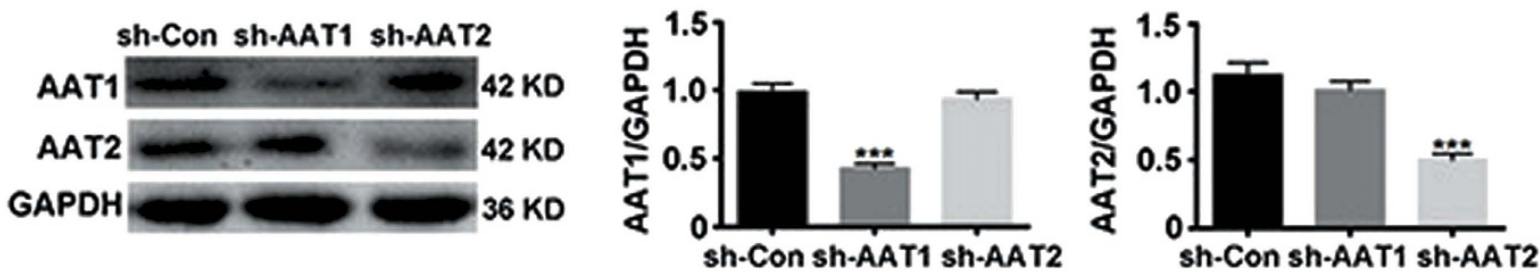

b
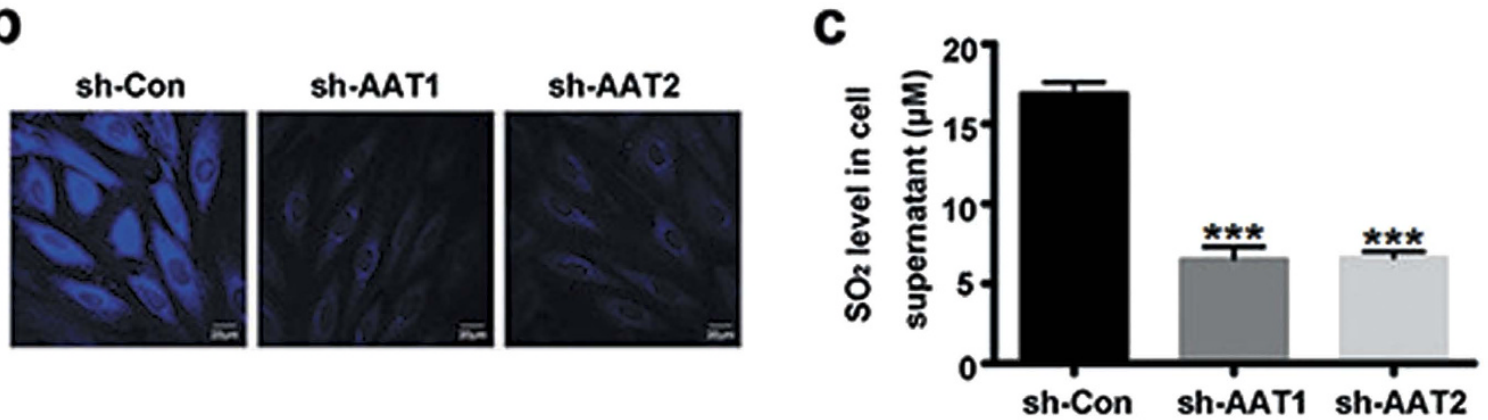

d
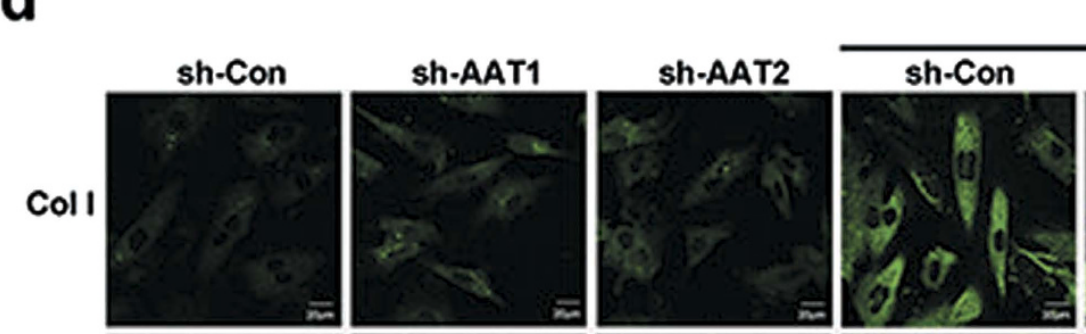

TGF- $\beta 1$
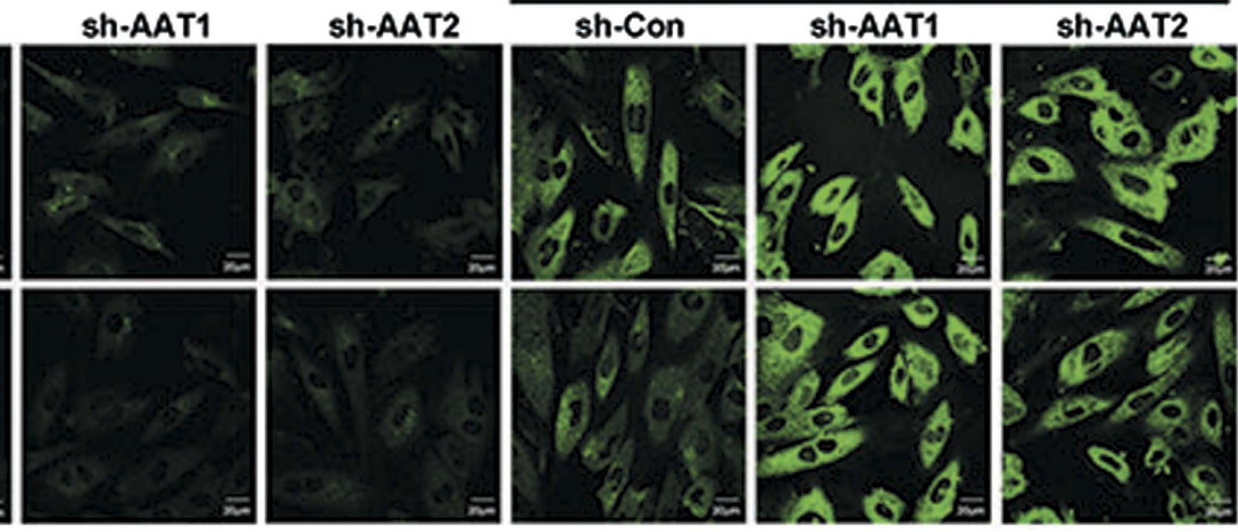

Col III
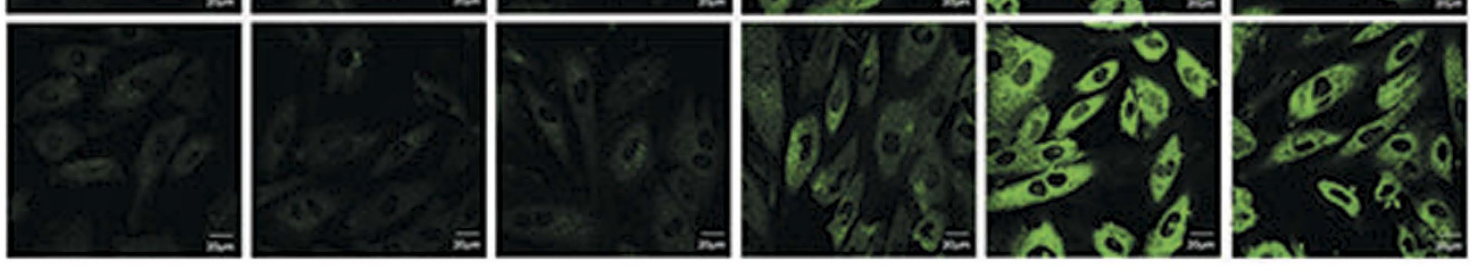

6

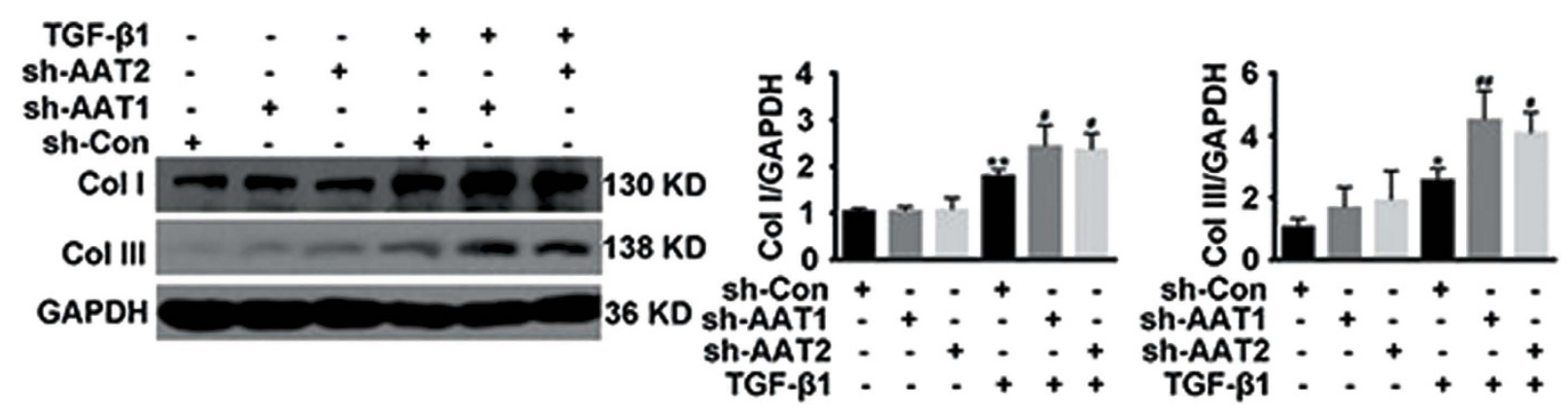

Figure 2. Endogenous $\mathrm{SO}_{2}$ knockdown exacerbated TGF- $\beta 1$-induced VSMC collagen remodeling. (a) Protein expression of AAT1 and AAT2 in VSMCs transfected with $2 \mu \mathrm{g}$ of control shRNA (sh-Con), AAT1 shRNA (sh-AAT1) or AAT2 shRNA (sh-AAT2) for $48 \mathrm{~h}$. (b) Representative fluorescent staining (blue) of endogenous $\mathrm{SO}_{2}$ in VSMCs transfected with Con, AAT1 or AAT2 shRNA for $48 \mathrm{~h}$. Scale bar, $20 \mu \mathrm{m}$. (c) $\mathrm{SO}_{2}$ content in supernatant from VSMCs transfected with Con, AAT1 or AAT2 shRNA for $48 \mathrm{~h}$. (d) Collagen I and III expression in VSMCs by confocal images. VSMCs in coverslips were transfected with Con, AAT1 or AAT2 shRNA before TGF- $\beta 1$ (10 ng/ml) stimulation for $24 \mathrm{~h}$. Scale bar, $20 \mu \mathrm{m}$. (e) Representative Western blot and quantification of collagen I and III in VSMCs transfected with Con, AAT1 or AAT2 shRNA before TGF- $\beta 1$ treatment. ${ }^{* *} P<0.001,{ }^{* \star} P<0.01$ or ${ }^{\star} P<0.05$ compared with Con shRNA, ${ }^{\# \#} P<0.01$ or ${ }^{\#} P<0.05$ compared with Con shRNA + TGF- $\beta 1$ group (ANOVA). Data are represented as mean $\pm \mathrm{SD}(\mathrm{n}=5)$. 
a

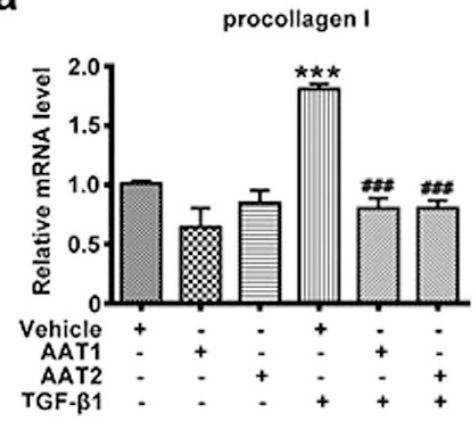

C

procollagen I

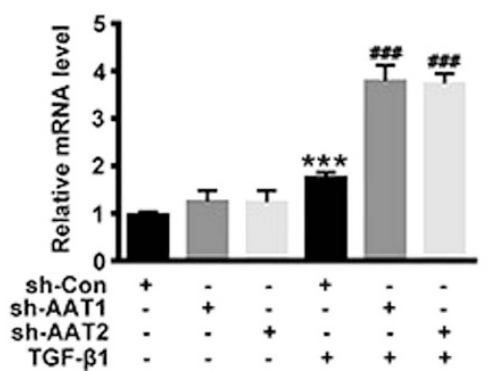

b

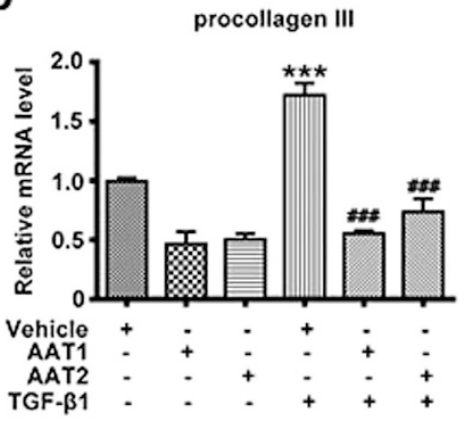

d

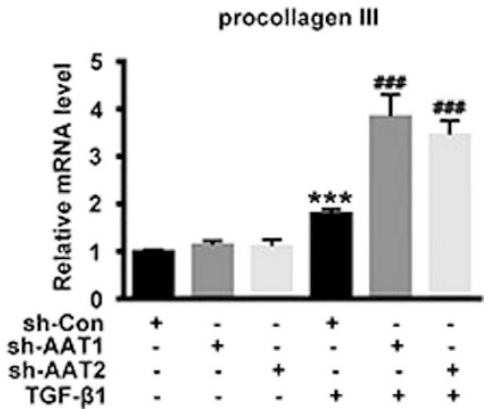

Figure 3. Endogenous $\mathrm{SO}_{2}$ regulated TGF- $\beta 1$-induced VSMC collagen remodeling through inhibiting collagen synthesis. (a,b) Procollagen I (a) and III (b) mRNA expression in VSMCs by real-time PCR. VSMCs were transfected with AAT1, AAT2 or vehicle plasmid before TGF- $\beta 1$ treatment for $24 \mathrm{~h}$. ${ }^{* *} P<0.001$ compared with vehicle, ${ }^{\# \# \#} P<0.001$ compared with vehicle + TGF- $\beta 1$ group (ANOVA). (c,d) Procollagen I (c) and III (d) mRNA expression in VSMCs by real-time PCR. VSMCs were transfected with Con, AAT1 or AAT2

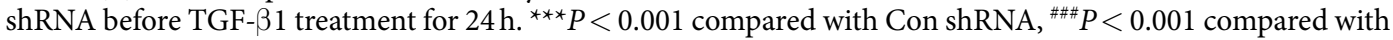
Con shRNA + TGF- $\beta 1$ group (ANOVA). Data are represented as mean $\pm \operatorname{SD}(n=5)$.

could markedly inhibit the TGF- $\beta 1$-induced phosphorylation of Smad2/3 (Fig. 5a). To examine if the expression of gene downstream of Smad2/3 was influenced by AAT overexpression, we detected the expression of plasminogen activator inhibitor-1 (PAI-1) using RT-PCR. The data showed that AAT1 or AAT2 overexpression could significantly reduce the TGF- $\beta 1$-upregulated mRNA expression of PAI-1 (Fig. $5 \mathrm{~b}$ ). On the contrary, AAT1 or AAT2 deficiency dramatically enhanced the TGF- $\beta 1$-induced phosphorylation of Smad2/3 (Fig. 5c). These data indicated that $\mathrm{Smad} 2 / 3$ signaling pathway might be involved in the modulation of endogenous $\mathrm{SO}_{2}$ on collagen remodeling in VSMCs.

Endogenous sulfur dioxide probably inhibited T $\beta R$ I phosphorylation during TGF- $\beta 1$-induced collagen remodeling in VSMCs. TGF- $\beta 1$ binds to T $\beta R I I$, which phosphorylates T $\beta$ RI. Then the phosphorylated T $\beta R$ I triggers $\mathrm{Smad} 2$ and $\mathrm{Smad} 3$ activation. Therefore, we tested whether endogenous $\mathrm{SO}_{2}$ could interfere with phosphorylation of T $\beta$ RI. Interestingly, TGF- $\beta 1$ promoted T $\beta$ RI phosphorylation in VSMCs, while AAT1 or AAT2 overexpression indeed downregulated the TGF- $\beta 1$-induced T $\beta$ RI phosphorylation (Fig. 6a). In contrast, AAT1 or AAT2 silencing aggravated the TGF- $\beta 1$-induced T $\beta$ RI phosphorylation (Fig. 6b). These results suggested that endogenous $\mathrm{SO}_{2}$ might inactivate the TGF- $\beta / \mathrm{Smad} 2 / 3$ signaling pathway during collagen remodeling of VSMCs through inhibiting T $\beta$ RI phosphorylation.

Endogenous sulfur dioxide deficiency promoted collagen remodeling mediated by TGF- $\beta 1 /$ Smad signaling pathway in VSMCs. To further explore whether TGF- $\beta 1 /$ Smad pathway mediated the regulatory effect of endogenous $\mathrm{SO}_{2}$ on collagen remodeling in VSMCs, we applied SB431542, an inhibitor of TGF- 31 /Smad signaling pathway, to VSMCs transfected with AAT1 or AAT2 shRNA. RT-PCR showed SB431542 almost completely abolished the AAT1- or AAT2-silencing induction in mRNA expression of procollagen I and III (Fig. 7a,b). Moreover, enhanced collagen I and III protein levels evoked by AAT1 or AAT2 knockdown were also greatly repressed by SB431542 (Fig. 7c,d), suggesting endogenous $\mathrm{SO}_{2}$ likely inhibited collagen remodeling at least in part by blocking the activation of TGF- $\beta 1 /$ Smad signaling pathway.

Ectopically expressing AAT abolished AAT deficiency-exacerbated collagen deposition in TGF- $\beta$ 1-stimulatd VSMCs. In order to exclude the collateral effects that were often produced by shRNA constructs, we ectopically expressed AAT1 or AAT2 in AAT1 or AAT2 deficiency VSMCs, respectively. Western blot analysis showed that transfecting with AAT1 plasmid increased the inhibited protein expression of AAT1 in 
a

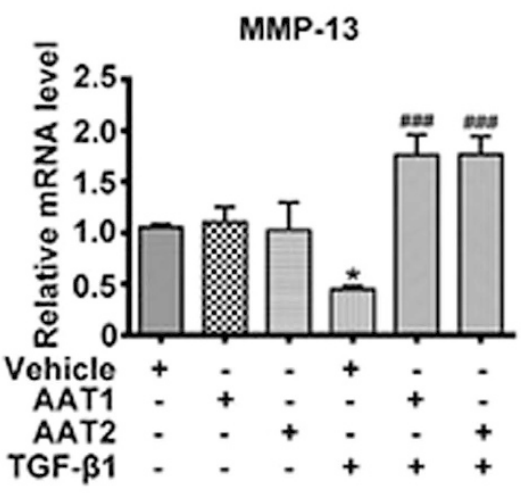

b

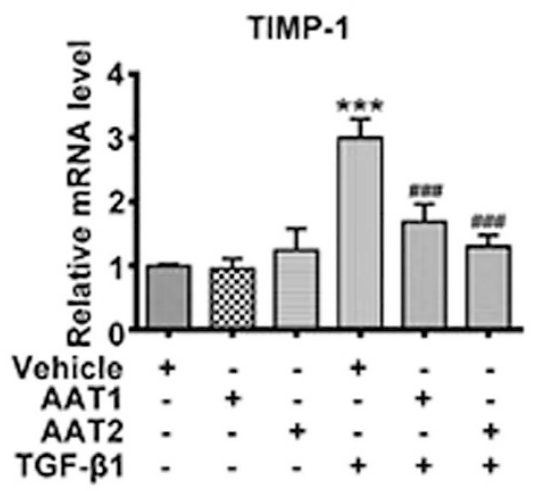

C

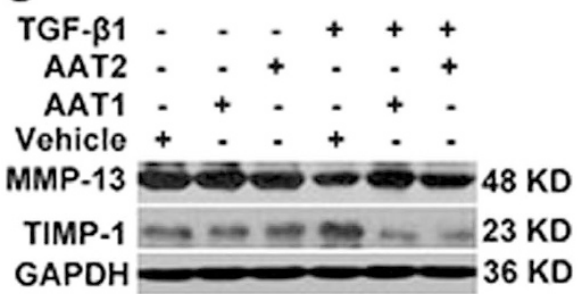

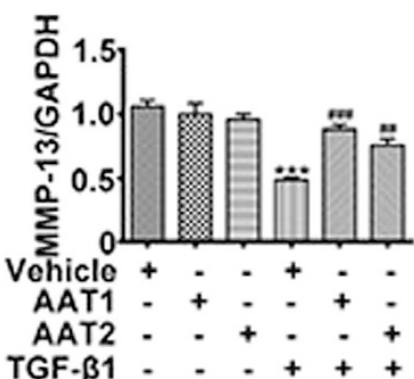

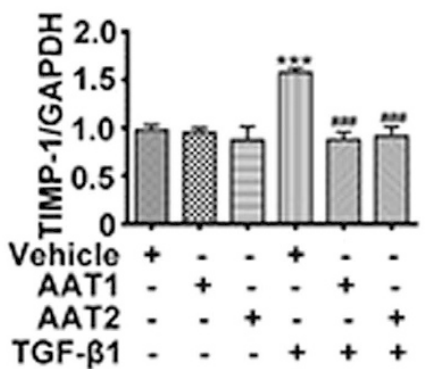

d
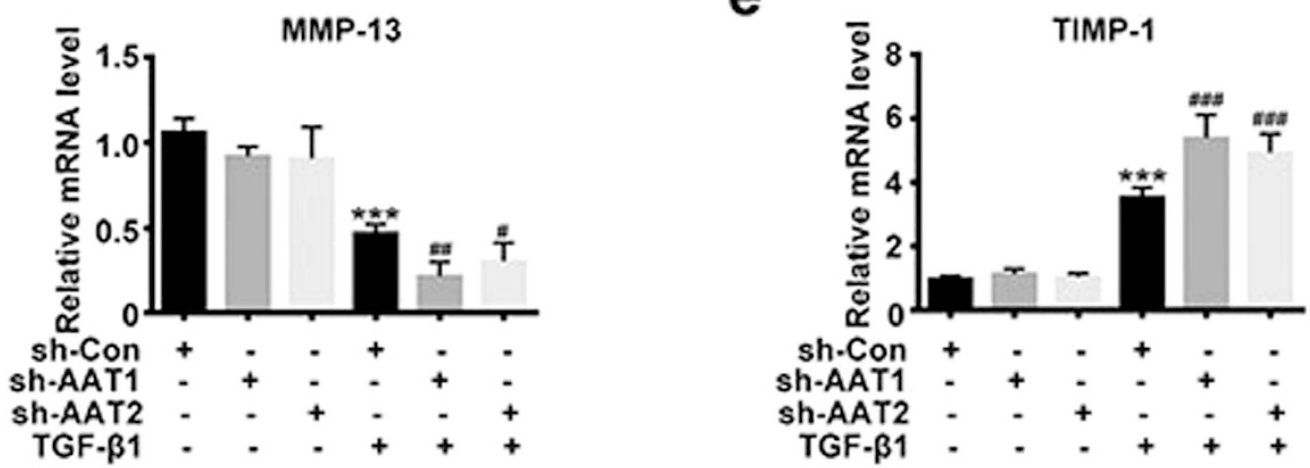

f
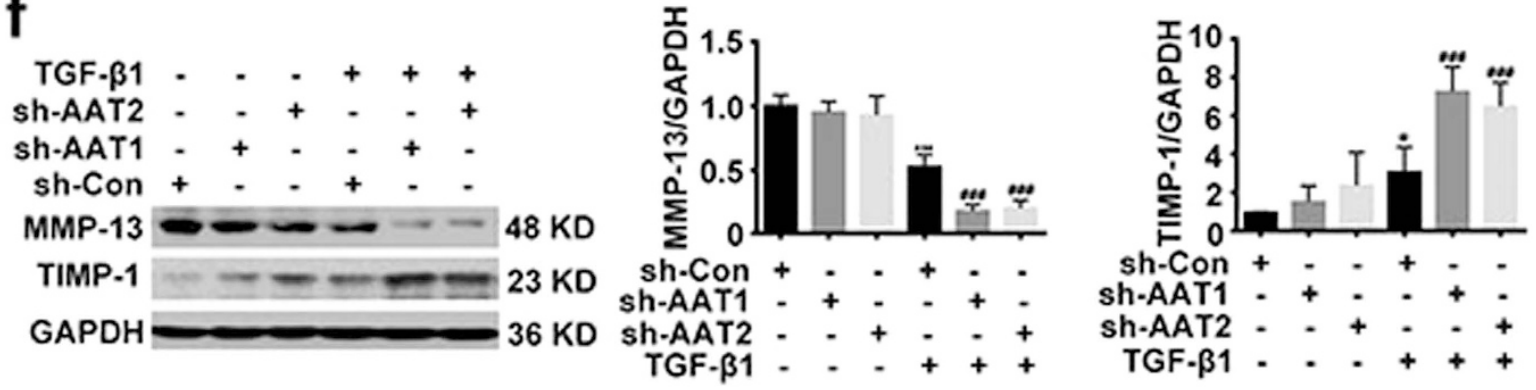

Figure 4. Endogenous $\mathrm{SO}_{2}$ regulated TGF- $\beta 1$-induced VSMC collagen remodeling through promoting collagen degradation. (a,b) MMP-13 (a) and TIMP-1 (b) mRNA expression in VSMCs by real-time PCR. VSMCs were transfected with AAT1, AAT2 or vehicle plasmid before TGF- $\beta 1$ treatment for $24 \mathrm{~h} .{ }^{\star} P<0.05$ or ${ }^{* * *} P<0.001$ compared with vehicle, ${ }^{\# \#} P<0.001$ compared with vehicle + TGF- $\beta 1$ group (ANOVA). (c) Representative Western blot and quantification of MMP-13 and TIMP-1 in VSMCs transfected with AAT1, AAT2 or vehicle plasmid before TGF- $\beta 1$ treatment for $24 \mathrm{~h} .{ }^{* *} P<0.001$ compared with vehicle, ${ }^{\# \# \#} P<0.001$ or ${ }^{\# \#} P<0.01$ compared with vehicle + TGF- $\beta 1$ group (ANOVA). (d,e) MMP-13 (d) and TIMP-1 (e) mRNA expression in VSMCs by real-time PCR. VSMCs were transfected with Con, AAT1 or AAT2 shRNA before TGF- $\beta 1$ treatment for $24 \mathrm{~h}$. ${ }^{* * *} P<0.001$ compared with vehicle, ${ }^{\#} P<0.05,{ }^{\# \#} P<0.01$ or ${ }^{\# \# \#} P<0.001$ compared with Con shRNA + TGF- $\beta 1$ group (ANOVA). (f) Representative Western blot and quantification of MMP13 and TIMP- 1 in VSMCs transfected with Con, AAT1 or AAT2 shRNA before TGF- $\beta 1$ treatment for $24 \mathrm{~h}$. ${ }^{* * *} P<0.001$ or ${ }^{\star} P<0.05$ compared with Con shRNA, ${ }^{\# \#} P<0.001$ compared with Con shRNA + TGF- $\beta 1$ group (ANOVA). Data are represented as mean $\pm \mathrm{SD}(\mathrm{n}=5)$. 
a

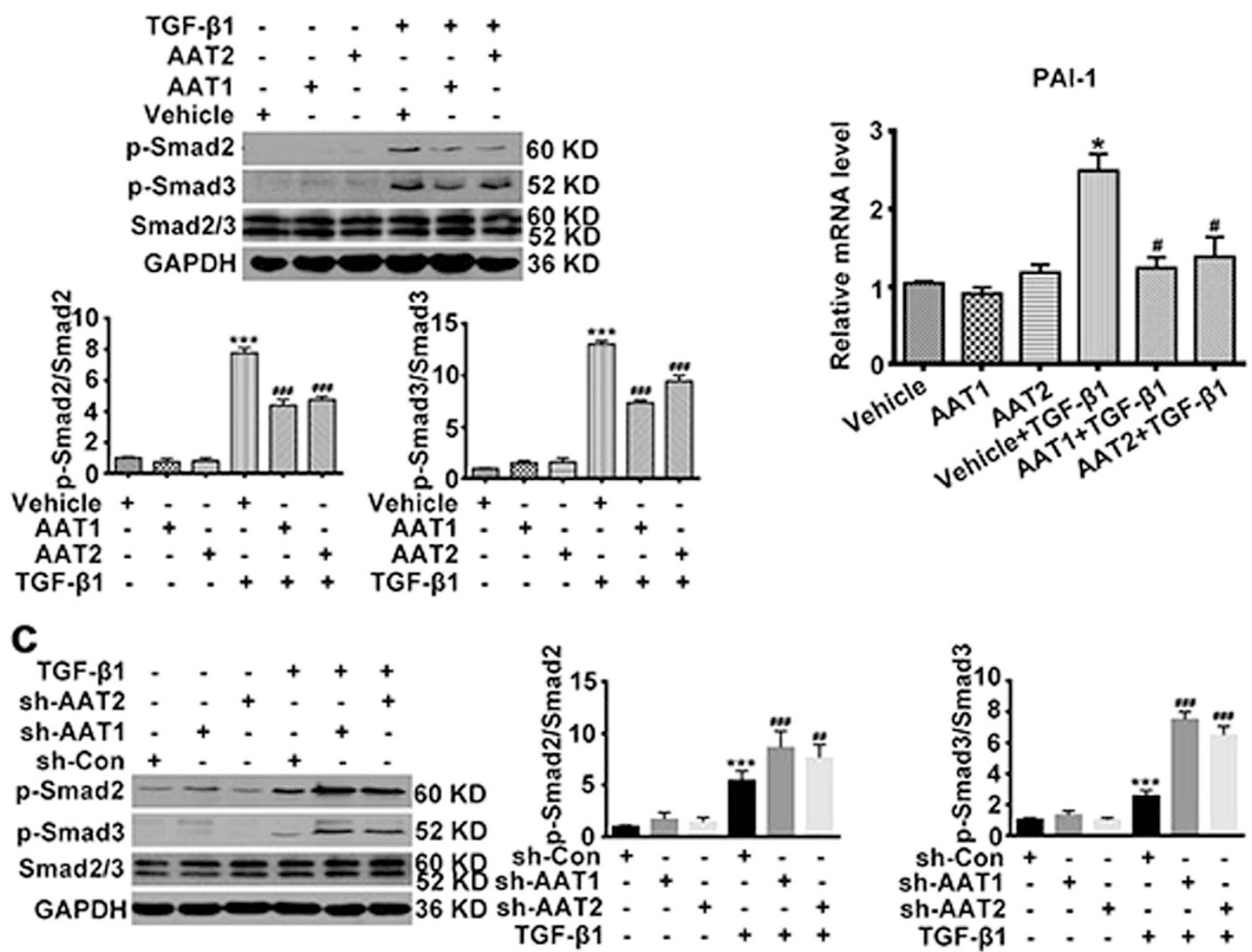

b

Figure 5. Endogenous $\mathrm{SO}_{2}$ inhibited TGF- $\beta 1$-induced Smad $2 / 3$ phosphorylation in VSMCs. (a) p-Smad 2 and $\mathrm{p}$-Smad 3 protein expression in VSMCs transfected with AAT1, AAT2 or vehicle plasmid before TGF- $\beta 1$ treatment for 1 h. ${ }^{* *} P<0.001$ compared with vehicle, ${ }^{\# \#} P<0.001$ compared with vehicle + TGF- $\beta 1$ group (ANOVA). (b) PAI-1 mRNA expression in VSMCs transfected with AAT1, AAT2 or vehicle plasmid before TGF- $\beta 1$ stimulation for $8 \mathrm{~h} .{ }^{\star} P<0.05$ compared with vehicle, ${ }^{*} P<0.05$ compared with vehicle + TGF- $\beta 1$ group (ANOVA). (c) p-Smad2 and p-Smad3 protein expression in VSMCs transfected with Con, AAT1 or AAT2 shRNA before TGF- $\beta 1$ treatment for $1 \mathrm{~h}$. ${ }^{* *} P<0.001$ compared with Con shRNA, ${ }^{\# \# \#} P<0.001$ or ${ }^{\# \#} P<0.01$ compared with Con shRNA + TGF- $\beta 1$ group (ANOVA). Data are represented as mean $\pm \mathrm{SD}(\mathrm{n}=4-5)$.

AAT1-scilencing VSMCs, and transfecting with AAT2 plasmid normalized AAT2 expression in AAT2-knocked down cells (Fig. 8a). Moreover, ectopic AAT1 or AAT2 expression significantly upregulated the inhibited $\mathrm{SO}_{2}$ level in AAT deficient VSMCs (Fig. 8b). Of note, AAT1 or AAT2 overexpression substantially abolished the excessive deposition of collagen I and III induced by AAT1 or AAT2 knocked-down in the TGF- $\beta 1$-treated VSMCs (Fig. 8a). And the enhanced mRNA levels of procollagen I and III by AAT1 or AAT2 deficiency were also retarded by ectopic AAT1 or AAT2 expression (Fig. 8c,d). These data verified that the effects produced by AAT shRNA constructs on collagen remodeling resulted from AAT deficiency.

Sulfur dioxide but not pyruvate protected against AAT deficiency-induced collagen remodeling in TGF- $\beta 1$-treated VSMCs. Since $\mathrm{SO}_{2}$ and pyruvate were generated equimolar from L-cysteine catalyzed by AAT, we next observed the effects of $100 \mu \mathrm{M} \mathrm{SO}_{2}$ derivatives $\left(\mathrm{Na}_{2} \mathrm{SO}_{3} / \mathrm{NaHSO}_{3}, 3: 1\right.$ mole ratios $)$ and $100 \mu \mathrm{M}$ ethyl pyruvate on the collagen remodeling induced by AAT deficiency. HPLC-FD analysis showed that $\mathrm{SO}_{2}$ derivatives at $100 \mu \mathrm{M}$ significantly upregulated the inhibited $\mathrm{SO}_{2}$ level by AAT1 or AAT2 deficiency, while ethyl pyruvate did not impact endogenous $\mathrm{SO}_{2}$ content (Fig. 9b). Western blot analysis demonstrated that $100 \mu \mathrm{M}$ $\mathrm{SO}_{2}$ derivatives could markedly inhibit AAT silencing-aggravated collagen I and III deposition in TGF- $\beta 1$-treatd VSMCs, while no inhibition was observed at $100 \mu \mathrm{M}$ ethyl pyruvate (Fig. 9a). Furthermore, $100 \mu \mathrm{M} \mathrm{SO}_{2}$ derivatives but not $100 \mu \mathrm{M}$ ethyl pyruvate reduced excessive collagen synthesis in AAT1- or AAT2-knocked down plus TGF- $\beta 1$-treated VSMCs (Fig. 9c,d). These data suggested that $\mathrm{SO}_{2}$ but not pyruvate exerted a crucially protective role in AAT deficiency promoted-collagen remodeling in TGF- $\beta 1$-treated VSMCs. 
a
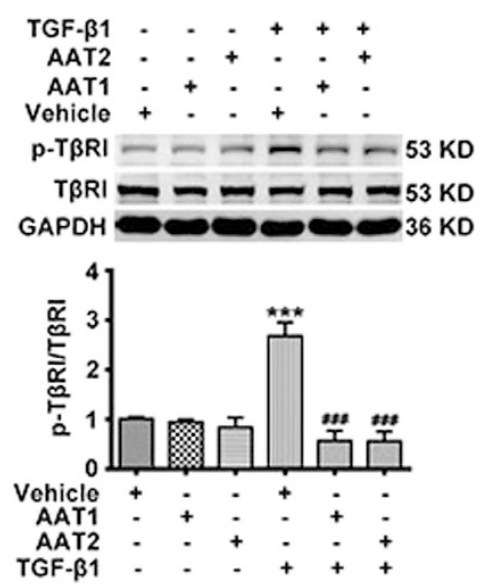

b
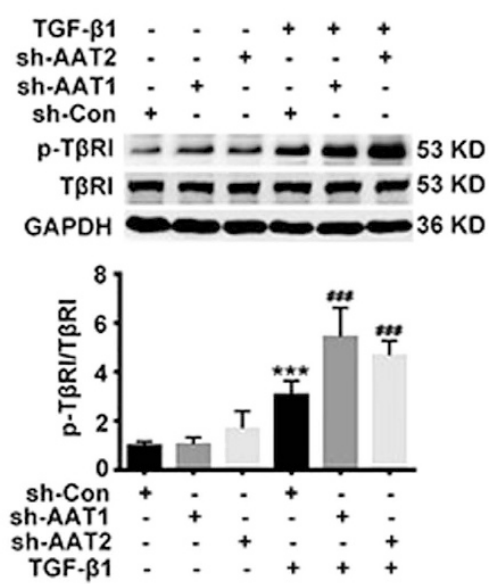

Figure 6. Endogenous $\mathrm{SO}_{2}$ inhibited TGF- $\beta 1$-induced T $\beta R I$ phosphorylation in VSMCs. (a) p-T $\beta R I$ and T $\beta$ RI protein expression in VSMCs transfected with AAT1, AAT2 or vehicle plasmid before TGF- $\beta 1$ treatment for $1 \mathrm{~h} .{ }^{* * *} P<0.001$ compared with vehicle, ${ }^{\# \#} P<0.001$ compared with vehicle + TGF- $\beta 1$ group (ANOVA). (b) p-T $\beta$ RI and T $\beta$ RI protein expression in VSMCs transfected with Con, AAT1 or AAT2 shRNA before TGF- $\beta 1$ treatment for $1 \mathrm{~h} .{ }^{* * *} P<0.001$ compared with Con shRNA, ${ }^{\# \#} P<0.001$ compared with Con shRNA + TGF- $\beta 1$ group (ANOVA). Data are represented as mean $\pm \mathrm{SD}(\mathrm{n}=5)$.

\section{Discussion}

With the increasing understanding about the function of hydrogen sulfide as gaseous signaling molecule in cardiovascular system, more and more attention has been paid to the physiological and pathophysiological functions of $\mathrm{SO}_{2}$, another important gasotransmitter in cardiovascular regulation. Recent studies have found that $\mathrm{SO}_{2}$ can be endogenously generated from sulfur-containing amino acid metabolism in human body ${ }^{7}$. L-cysteine can be oxidized into L-cysteine sulfinate by cysteine dioxygenase, the latter can be transformed into $\beta$-sulfinylpyruvate by AAT, then spontaneously decomposes to pyruvate and $\mathrm{SO}_{2}{ }^{8}$. A part of $\mathrm{SO}_{2}$ in vivo can quickly combine with water to form sulphite, while other exists in gaseous form. Previous Studies found that exogenous $\mathrm{SO}_{2}$ donor inhibited the hypoxic pulmonary vascular remodeling ${ }^{9}$. In addition, Liu et al. reported that $\mathrm{SO}_{2}$ suppressed aortic VSMCs proliferation ${ }^{15}$. However, it's still unclear about whether endogenous $\mathrm{SO}_{2}$ regulates collagen remodeling in VSMCs, and its underlying mechanisms. Therefore, we overexpressed $\mathrm{SO}_{2}$ generating enzyme, AAT in VSMCs or knocked down AAT with shRNA, demonstrating endogenous $\mathrm{SO}_{2}$ inhibited the TGF- $\beta 1$-induced excessive collagen deposition in VSMCs and its possible mechanisms.

Maintenance of extracellular matrix (ECM) is one of the major functions of VSMCs. Disturbance of ECM homeostasis leads to excessive ECM deposition, much of which is produced by VSMCs, is a common consequence of cardiovascular diseases such as atherosclerosis, hypertension, and restenosis after coronary angioplasty ${ }^{16-18}$. Most of ECM proteins within vascular walls are collagen I and $\mathrm{III}^{18}$. Therefore, searching for endogenous molecules regulating collagen remodeling in VSMCs, can help to protect from the occurrence and development of cardiovascular disease. $\mathrm{SO}_{2}$, a gaseous signaling molecule, can be endogenously generated in many cells, including VSMCs ${ }^{19}$. To explore the effect of endogenous $\mathrm{SO}_{2}$ on collagen remodeling in VSMCs, we used immunofluorescence staining and Western blot to detect the protein expression of collagen I and III in VSMCs. The data showed that endogenous $\mathrm{SO}_{2}$ significantly inhibited the TGF- $\beta 1$-induced collagen I and III protein levels.

Collagen remodeling contains two major links, namely excessively increased collagen synthesis and/or reduced collagen degradation. Collagen synthesis reflects in the transcription and translation of procollagen gene. So next we detected the effect of endogenous $\mathrm{SO}_{2}$ on collagen synthesis. We found that endogenous $\mathrm{SO}_{2}$ markedly suppressed the TGF- $\beta 1$-induced procollagen I and III mRNA levels, suggesting that endogenous $\mathrm{SO}_{2}$ could inhibit collagen synthesis in VSMCs.

The balance between degradation of ECM is guaranteed by MMPs and TIMPs ${ }^{20,21}$. MMPs consist of a family of $\mathrm{Zn}$-dependent endopeptidases that degrade ECM and basement membrane. They take part in tissue remodeling, cell infiltration and tumor invasion. For example, MMP-2, MMP-9 and MMP-13 are reported to have pivotal roles in vascular remodeling in several disease states ${ }^{20-22}$. MMP-2 mainly degrades type-IV, V, VII, X and XI collagen, gelatin, fibronectin, laminin and elastin. MMP-9 mainly degrades type-IV, V, VII, X collagen, gelatin, elastin, laminin, proteoglycan, fibronectin and entacin. Of note, MMP-13 degrades type-I, II, III, IV, IX, X and XIV collagen, fibronectin, tenascin-C, proteoglycan and gelatin ${ }^{22}$. MMPs activation can be suppressed by their endogenous inhibitors, the TIMPs. Four types of TIMPs have been found, of which TIMP-1 is the important inhibitor of MMP-1, $-3,-9$ and $-13^{23}$. Therefore, in this study we detected the effect of endogenous $\mathrm{SO}_{2}$ on $\mathrm{MMP}-$ 13 and TIMP- 1 mRNA and protein expressions in VSMCs. We found that TGF- $\beta 1$ downregulated the mRNA and protein expressions of MMP-13, and upregulated the mRNA and protein levels of TIMP-1. Endogenous $\mathrm{SO}_{2}$ could dramatically increase the TGF- $\beta 1$-downregulated MMP- 13 level, and decrease the TGF- $\beta 1$-upregulated TIMP-1 level, suggesting endogenous $\mathrm{SO}_{2}$ could promote collagen degradation. 
a

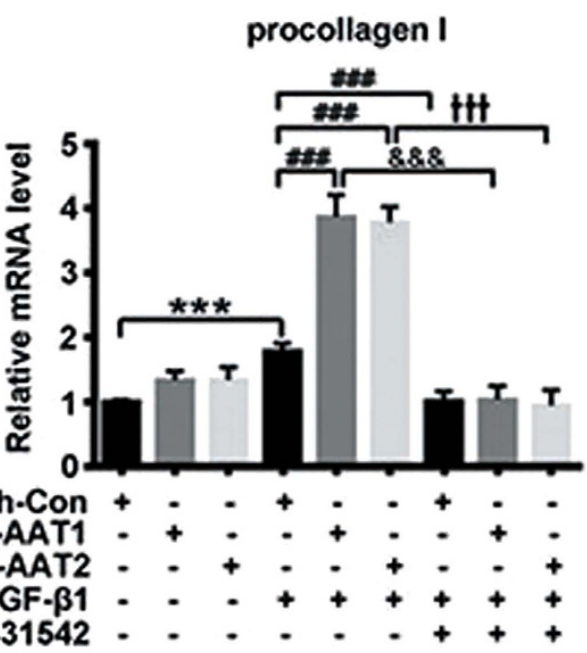

b

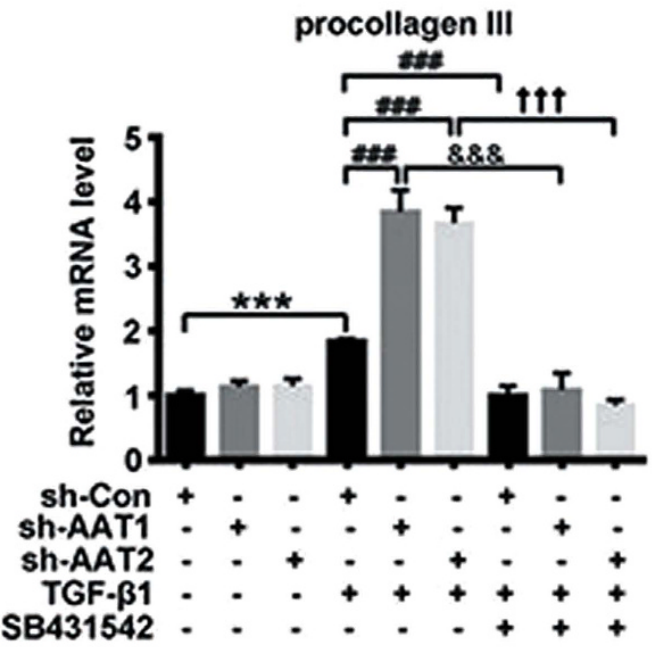

C

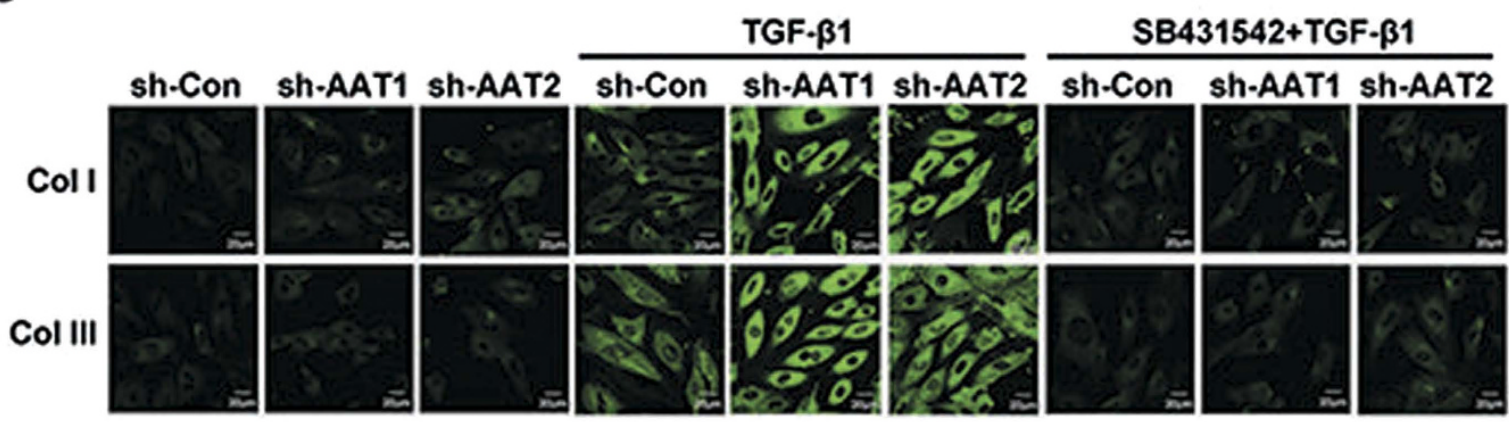

d

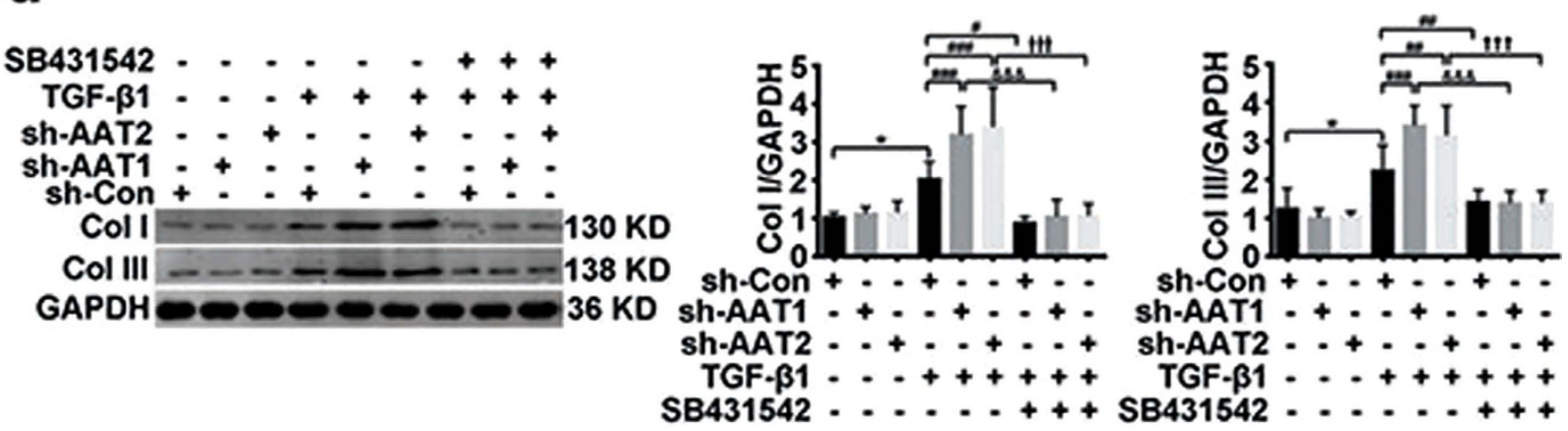

Figure 7. The activation of TGF- $\beta 1 /$ Smad signaling pathway mediated endogenous $\mathrm{SO}_{2}$ deficiency exacerbating collagen remodeling in VSMCs. (a,b) Procollagen I (a) and III (b) mRNA expression in VSMCs by real-time PCR. VSMCs transfected with Con, AAT1 or AAT2 shRNA were pretreated with SB431542 $(5 \mu \mathrm{mol} / \mathrm{L})$ for $1 \mathrm{~h}$, and then stimulated with TGF- $\beta 1$ for $24 \mathrm{~h}$. (c) Collagen I and III expression in VSMCs by confocal images. VSMCs in coverslips transfected with Con, AAT1 or AAT2 shRNA were pretreated with SB431542 $(5 \mu \mathrm{mol} / \mathrm{L})$ for $1 \mathrm{~h}$, and then stimulated with TGF- 31 for $24 \mathrm{~h}$. Scale bar, $20 \mu \mathrm{m}$. (d) Representative Western blot and quantification of collagen I and III in VSMCs. VSMCs transfected with Con, AAT1 or AAT2 shRNA were pretreated with SB431542 $(5 \mu \mathrm{mol} / \mathrm{L})$ for $1 \mathrm{~h}$, and then stimulated with TGF- $\beta 1$ for $24 \mathrm{~h}$. ${ }^{* *} P<0.001$ or ${ }^{\star} P<0.05$ compared with Con shRNA, ${ }^{\# \#} P<0.001$, ${ }^{\# *} P<0.01$ or ${ }^{\#} P<0.05$ compared with Con shRNA + TGF- $\beta 1$ group, ${ }^{\& \& \&} P<0.001$ compared with AAT1 shRNA + TGF- $\beta 1$ group, and ${ }^{+++} P<0.001$ compared with AAT2 shRNA + TGF- $\beta 1$ group (ANOVA). Data are represented as mean \pm SD $(n=5)$.

TGF- $\beta 1$ is a potent profibrotic factor that is involved in vascular fibrosis ${ }^{24-26}$. Previous study reported that TGF- $\beta 1$ could stimulate collagen synthesis ${ }^{4,27,28}$, and inhibit collagen degradation ${ }^{3,29,30}$. Classic TGF signaling pathway is realized by Smad family members ${ }^{3,4,12}$. Activated TGF- $\beta 1$ combines to T $\beta$ RII, which phosphorylates T $\beta R I$. Then the phosphorylated T $\beta$ RI triggers Smad 2 and Smad3 phosphorylation. The phosphorylated Smad2/3 forms a complex with Smad4, translocate from cytoplasm into the nucleus and activate the transcription of procollagen ${ }^{13,14}$. Previous studies have showed that TGF- $\beta 1$ activated collagen remodeling in VSMCs mainly 

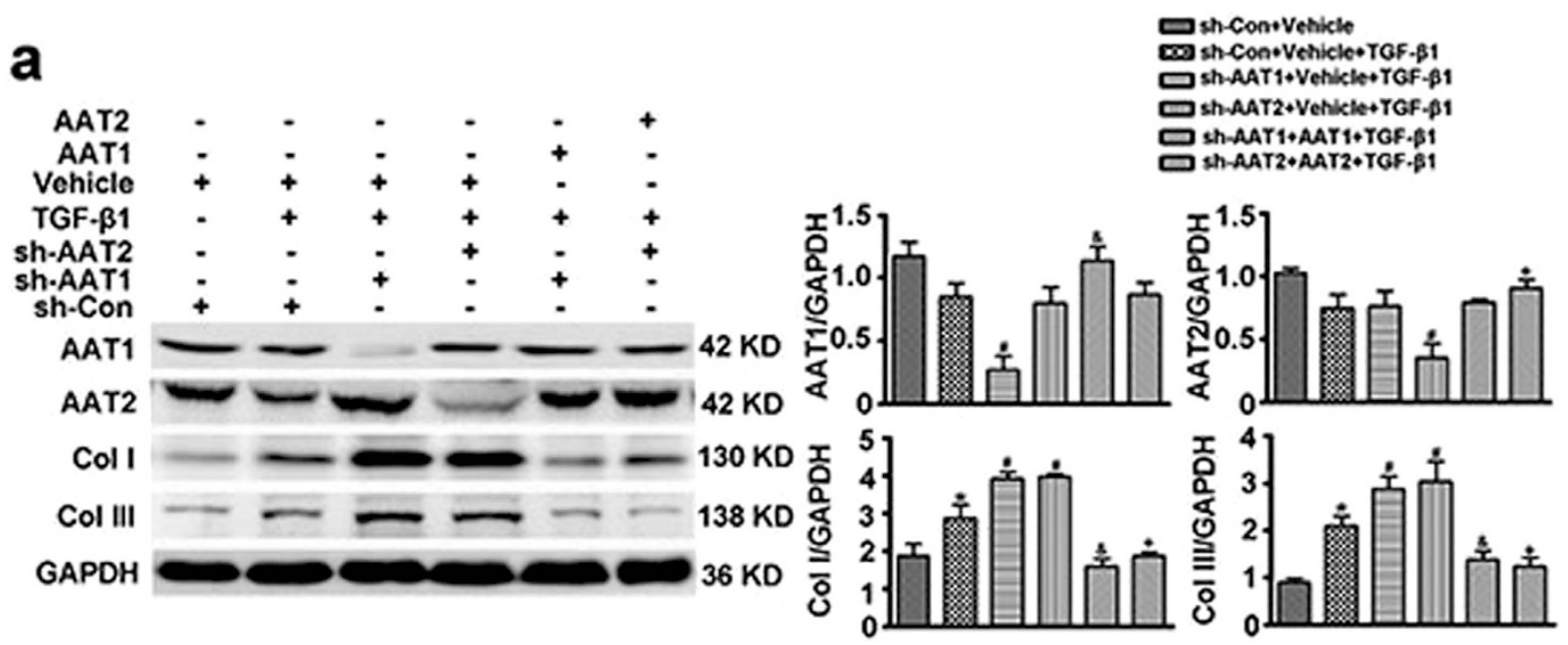

b
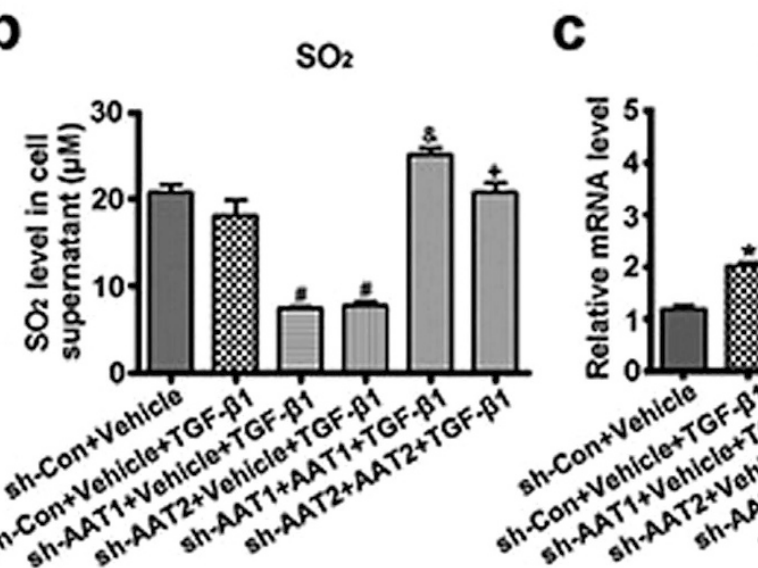

procollagen I

d

procollagen III

Figure 8. Ectopically expressing AAT abolished AAT deficiency-aggravated collagen remodeling in TGF31-treated VSMCs. (a) Representative Western blot and quantification of AAT1, AAT2, collagen I and III in VSMCs. VSMCs were co-transfected with Con shRNA and vehicle, AAT1 shRNA and vehicle, AAT2 shRNA and vehicle, AAT1 shRNA and AAT1, or AAT2 shRNA and AAT2 for $48 \mathrm{~h}$, and then stimulated with TGF- $\beta 1$ for $24 \mathrm{~h}$. (b) $\mathrm{SO}_{2}$ level in cell supernatant detected by HPLC-FD. (c,d) Procollagen I (c) and III (d) mRNA expression in VSMCs by real-time PCR. VSMCs were co-transfected with Con shRNA and vehicle, AAT1 shRNA and vehicle, AAT2 shRNA and vehicle, AAT1 shRNA and AAT1, or AAT2 shRNA and AAT2 for $48 \mathrm{~h}$, and then stimulated with TGF- $\beta 1$ for $24 \mathrm{~h}$. ${ }^{\star} P<0.05$ compared with Con shRNA + vehicle, ${ }^{\sharp} P<0.05$ compared with Con shRNA + vehicle + TGF- $\beta 1$ group, ${ }^{\circledR} P<0.05$ compared with AAT1 shRNA + vehicle + TGF- $\beta 1$ group, and ${ }^{+} P<0.05$ compared with AAT 2 shRNA + vehicle + TGF- $\beta 1$ group (ANOVA). Data are represented as mean $\pm \operatorname{SD}(\mathrm{n}=4-5)$.

through TGF- $\beta /$ Smad signaling pathway ${ }^{3,4,31}$. TGF- $\beta 1$ could significantly increase the collagen protein expression in VSMCs through Smad2/3 signaling pathway ${ }^{4,16}$. Our present study showed that endogenous $\mathrm{SO}_{2}$ markedly inhibited the TGF- $\beta 1$-induced phosphorylation of Smad 2 and Smad3 in VSMCs. In order to further explore how endogenous $\mathrm{SO}_{2}$ blocked the Smad signaling pathway, we detected the phosphorylation level of T $\beta$ RI. The data indicated that endogenous $\mathrm{SO}_{2}$ suppressed the phosphorylation of T $\beta \mathrm{RI}$. And SB431542, an inhibitor of TGF- $\beta 1 /$ Smad signaling pathway, could significantly abolish the promoting effect of endogenous $\mathrm{SO}_{2}$ deficiency on TGF- $\beta 1$-induced collagen remodeling in VSMCs. These results suggested that endogenous $\mathrm{SO}_{2}$ alleviated the collagen remodeling in VSMCs at least in part by inhibiting TGF- $\beta /$ Smad signaling pathway.

The limitation of the present study involved the employment of exclusively one shRNA construct targeting either AAT1 or AAT2, and compared to only one control for all experiments. Considering the collateral effects that were often produced by such constructs, we used ectopically expressing AAT in knocked-down cells. The data showed that ectopic AAT1 or AAT2 expression upregulated the repressed $\mathrm{SO}_{2}$ level in AAT knocked down-VSMCs. As a consequence, AAT1 or AAT2 overexpression abolished AAT silencing-induced collagen I and III deposition in TGF- $\beta 1$-treated VSMCs possibly via reducing collagen synthesis. These results supported the assumption that AAT1 and AAT2 shRNA used in the present study targeted AAT1 and AAT2 genes, respectively. AAT shRNA-induced exacerbation of collagen remodeling might result from AAT deficiency, other than the off-target effects. 

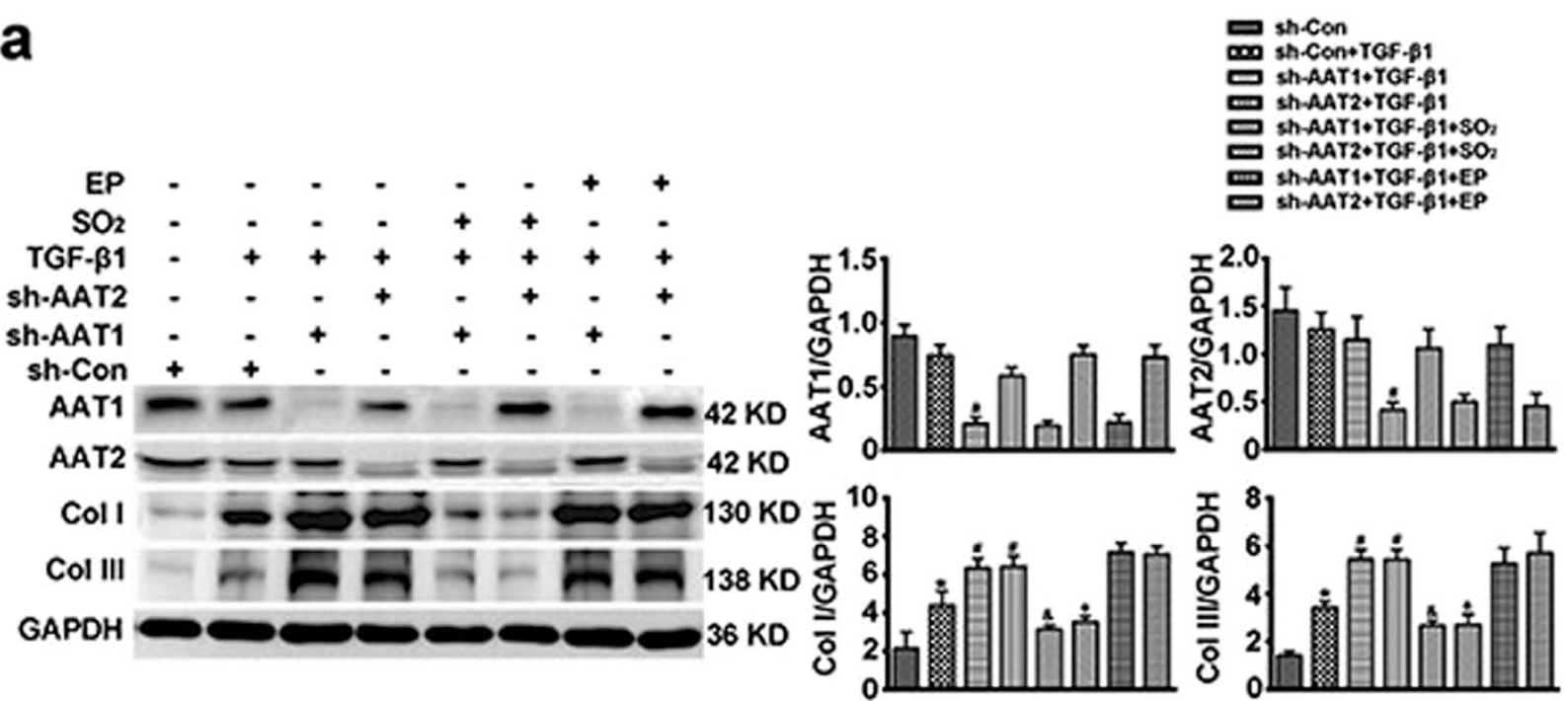

b

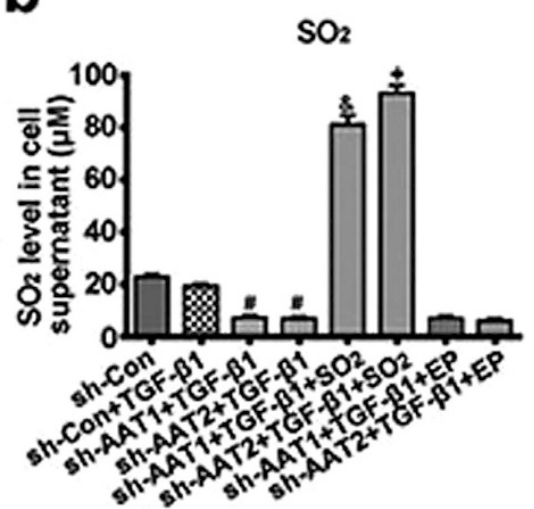

C

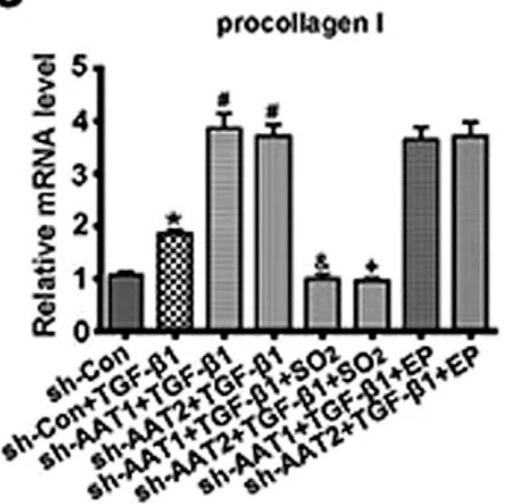

d

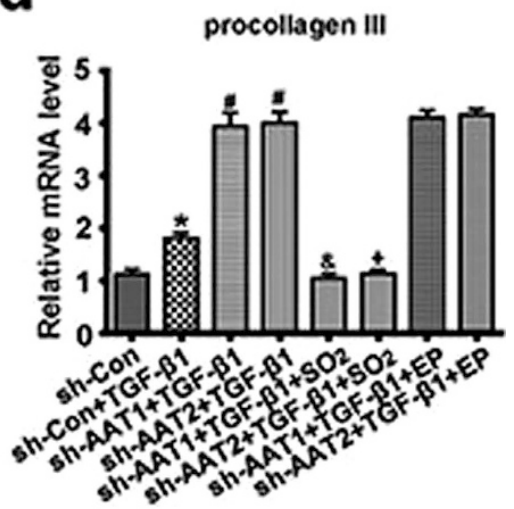

Figure 9. $\mathrm{SO}_{2}$ derivatives but not ethyl pyruvate abolished AAT deficiency-promoted collagen remodeling in TGF- $\beta 1$-treated VSMCs. (a) Representative Western blot and quantification of AAT1, AAT2, collagen I and III in VSMCs. VSMCs were transfected with Con shRNA, AAT1 shRNA or AAT2 shRNA for $48 \mathrm{~h}$, pretreated with $\mathrm{SO}_{2}$ derivatives $\left(\mathrm{NaHSO}_{3} / \mathrm{Na}_{2} \mathrm{SO}_{3}, 100 \mu \mathrm{M}\right)$ or ethyl pyruvate $(\mathrm{EP}, 100 \mu \mathrm{M})$ for $1 \mathrm{~h}$, and then stimulated with TGF- $\beta 1$ for 24 h. (b) SO level in cell supernatant detected by HPLC-FD. (c,d) Procollagen I (c) and III (d) mRNA expression in VSMCs by real-time PCR. VSMCs were transfected with Con shRNA, AAT1 shRNA or AAT2 shRNA for $48 \mathrm{~h}$, pretreated with $\mathrm{SO}_{2}$ derivatives $\left(\mathrm{NaHSO}_{3} / \mathrm{Na}_{2} \mathrm{SO}_{3}, 100 \mu \mathrm{M}\right)$ or ethyl pyruvate (EP, $100 \mu \mathrm{M})$ for $1 \mathrm{~h}$, and then stimulated with TGF- $\beta 1$ for $24 \mathrm{~h} .{ }^{\star} P<0.05$ compared with Con shRNA, ${ }^{*} P<0.05$ compared with Con shRNA + TGF- $\beta 1$ group, ${ }^{\circledR} P<0.05$ compared with AAT 1 shRNA + TGF- $\beta 1$ group, and ${ }^{+} \mathrm{P}<0.05$ compared with AAT2 shRNA + TGF- $\beta 1$ group (ANOVA). Data are represented as mean $\pm \mathrm{SD}$ $(\mathrm{n}=4-5)$.

Endogenous $\mathrm{SO}_{2}$ was produced from L-cysteine in a two-step reaction, in which the later step was catalyzed by AAT and resulted in equimolar pyruvate as well ${ }^{7,8,32}$. Previous studies showed that pyruvate could modulate TGF- $\beta$ signaling ${ }^{33,34}$. However, whether the effects of AAT manipulation on collagen remodeling were caused by $\mathrm{SO}_{2}$ or pyruvate had not been elucidated. Here, we added exogenous $\mathrm{SO}_{2}$ derivatives or pyruvate in AAT-knocked down VSMCs. Considering the instability of pyruvate, ethyl pyruvate, a simple aliphatic ester derived from pyruvic acid, was widely implicated in scientific research instead of pyruvate ${ }^{34,35}$. Since $\mathrm{SO}_{2}$ and pyruvate were generated equimolar from L-cysteine catalyzed by $\mathrm{AAT}^{7,8,32}$, VSMCs were pretreated with $100 \mu \mathrm{M} \mathrm{SO}_{2}$ derivatives or $100 \mu \mathrm{M}$ ethyl pyruvate in the present study. The results showed that $\mathrm{SO}_{2}$ derivatives at $100 \mu \mathrm{M}$ significantly inhibited AAT silencing-exacerbated collagen I and III deposition in TGF- $\beta 1$-treated VSMCs, while no inhibition was observed at $100 \mu \mathrm{M}$ ethyl pyruvate. These data demonstrated that $\mathrm{SO}_{2}$ generated by AAT but not pyruvate played a crucially protective role against collagen remodeling in AAT knocked-down VSMCs with TGF- $\beta 1$ stimulation.

In conclusion, we discovered an inhibitory effect of endogenous $\mathrm{SO}_{2}$ on TGF- $\beta 1$-induced collagen remodeling in VSMCs via suppressing collagen synthesis and promoting collagen degradation. The underlying mechanism might involve inhibiting the T $\beta \mathrm{RI}$ phosphorylation by endogenous $\mathrm{SO}_{2}$ to block the $\mathrm{Smad} 2 / 3$ signaling pathway activation. These findings suggest that endogenous $\mathrm{SO}_{2}$ may be a promising therapeutic target for vascular collagen remodeling related cardiovascular diseases such as hypertension. 


\section{Methods}

Cell culture. Rat A7r5 VSMCs were obtained from the American Type Culture Collection (Manassas, VA, USA). Cells were cultured in Dulbecco's modified Eagle's medium (DMEM) containing $10 \% \mathrm{FBS}, 2 \mathrm{mmol} / \mathrm{l} \mathrm{glu}$ tamine and $20 \mathrm{mmol} / \mathrm{l} \mathrm{HEPES}(\mathrm{pH} 7.4)$ in an atmosphere of $5 \% \mathrm{CO}_{2}$ at $37^{\circ} \mathrm{C}$.

Overexpression of AAT1 or AAT2 in VSMCs. The cDNA fragment encoding the full-length rat AAT1 (NM_012571.2) or AAT2 (NM_013177.2) was amplified by PCR and inserted into the pIRES2 vector, and the resultant plasmid AAT1 or AAT2 was verified by DNA sequencing. A7r5 VSMCs were then transfected with AAT1, AAT2 or vehicle plasmid using JetPEI reagent according to the manufacturer's instructions (Polyplus Transfection, Illkirch, France).

Knockdown of AAT1 or AAT2 in VSMCs. Rat AAT1 shRNA and AAT2 shRNA were both from OriGene Technologies (Rockville, MD, USA). A7r5 VSMCs were seeded in 6-well plates to 60-80\% confluence. AAT1 shRNA, AAT2 shRNA and control shRNA were respectively transfected into A7r5 VSMCs using the JetPEI reagent according to the manufacturer's instructions (Polyplus Transfection, Illkirch, France).

Determination of mRNA expressions of procollagen I and III, MMP-13 and TIMP-1 by quantitative real-time polymerase chain reaction. Total RNA was extracted using the Trizol reagent and transcribed into cDNA using oligo (dT) primer and M-MLV reverse transcriptase. Quantitative real-time polymerase chain reaction (RT-PCR) was performed on an ABI PRISM 7300 instrument (Applied Biosystems, Foster, CA, USA). The amplification conditions for the cDNA were: denaturing at $94^{\circ} \mathrm{C}$ for $30 \mathrm{~s}$, annealing and polymerizing at $60^{\circ} \mathrm{C}$ for $1 \mathrm{~min}$ for 40 cycles. Samples and standards were determined in triplicate. TaqMan probes were modified by $5^{\prime}$-FAM and $3^{\prime}$-TAMRA.

Sequences of the primers and probes were: for procollagen I, forward, $5^{\prime}$-CTTGTTGCTGAGGGC AACAG-3', reverse, $5^{\prime}$-GCAGGCGAGATGGCTTATTC-3', Taqman probe, 5' -ATTCACCTACACTGTCCTT GTCGATGGCTG-3'; for procollagen III, forward, $5^{\prime}$-GAAAAAACCCTGCTCGGAATT- $3^{\prime}$, reverse, $5^{\prime}$-ATCC ATCTTGCAGCCTTGGT-3', Taqman probe, 5' -AGAGACCTGAAATTCTGCCACCCTGAACTC-3'; for MMP13, forward, 5' - CTTCTGGCACACGCTTTTCC-3', reverse, 5' -GCTCATGGGCAGCAACAATA -3', Taqman probe, 5'-CCTGGACCAAACCTTGGCGG -3'; for TIMP-1, forward, 5' -AGCCCTGCTCAGCAAAAGG-3', reverse, 5' - CTGTCCACAAGCAATGACTGTCA-3', Taqman probe, $5^{\prime}$ - CTTCGTAAAGACCTATAGTGCTGGCTG-3 '; for PAI-1, forward, 5' -GGTCAAGATCGAGGTGAACGA-3', reverse, 5' -GCGGGCTGAGACTAGAATGG, Taqman probe, 5' -CGGCACAGTGGCGTCTTCCTCC-3'; and for $\beta$-actin, forward, $5^{\prime}$ - ACCCG CGAGTACAACCTTCTT-3', reverse, 5' -TATCGTCATCCATGGCGAACT-3', Taqman probe, 5' -CCTCCG TCGCCGGTCCACAC-3'.

Western blot analysis. A7r 5 cells $\left(5 \times 10^{4}\right)$ were incubated in 6 -well plates. When cells were grown to $60-70 \%$ confluences, they were treated as follows. In the first series, cells were transfected with $2 \mu \mathrm{g}$ of vehicle, AAT1 or AAT2 plasmid. After $24 \mathrm{~h}$, they were starved in DMEM with $0.5 \%$ FBS before TGF- $\beta 1(10 \mathrm{ng} / \mathrm{ml})$ treatment for $24 \mathrm{~h}$ or $1 \mathrm{~h}$. In the second series, cells were transfected with $2 \mu \mathrm{g}$ of control shRNA, AAT1 shRNA or AAT2 shRNA for $24 \mathrm{~h}$. Then they were starved for $24 \mathrm{~h}$ followed by TGF- $31(10 \mathrm{ng} / \mathrm{ml})$ treatment for $24 \mathrm{~h}$ or $1 \mathrm{~h}$. In the third series, cells were transfected with control shRNA, AAT1 shRNA or AAT2 shRNA for $24 \mathrm{~h}$, staved for $24 \mathrm{~h}$, treated with SB431542 $(5 \mu \mathrm{mol} / \mathrm{L})$ for $1 \mathrm{~h}$, and then stimulated with TGF- $\beta 1(10 \mathrm{ng} / \mathrm{ml})$ for $24 \mathrm{~h}$.

These samples were harvested and lysed in lysis buffer $(0.5 \mathrm{mmol} / \mathrm{L}$ EDTA, $10 \mathrm{mmol} / \mathrm{L}$ Tris- $\mathrm{HCl}, \mathrm{pH} 7.4$, $0.3 \mathrm{~mol} / \mathrm{L}$ sucrose, and protease inhibitor cocktail) as previously described ${ }^{15}$. Equal amounts of protein were resolved on SDS-PAGE gels and transferred onto nitrocellulose membranes. Non-specific bindings were blocked by incubation in 5\% milk blocking buffer. The primary antibodies anti-AAT1 and anti-AAT2 were from Sigma-Aldrich Corporation (St Louis, MO, USA), anti-collagen I and anti-collagen III were from Abcam (Cambridge, MA, USA), anti-MMP-13 and anti-TIMP-1 were from Santa Cruz Biotechnology (Santa Cruz, CA, USA), anti-phospho-Smad2, anti-phospho-Smad3 and anti-Smad2/3 were from Cell Signaling Technology (Danvers, MA, USA), and anti-GAPDH were form Kangcheng (Shanghai, China). After incubation, each primary antibody bound with their respective specific horseradish peroxidase-conjugated secondary antibodies (Santa Cruz Biotechnology) and the bands were visualized using enhanced chemiluminescence detection kit (Thermo Scientific, Rockford, IL, USA). The densitometric analysis of the positive bands was performed using AlphaEaseFC (Alpha Innotech Corporation, San Leandro, CA, USA).

Collagen I and III expression in VSMCs by immunofluorescence and confocal microscopy. VSMCs were plated on glass coverslips. When cells were grown to $60-70 \%$ confluences, they were treated as follows. In the first series, cells were transfected with vehicle, AAT1 or AAT2 plasmid. After $24 \mathrm{~h}$, they were starved in DMEM with $0.5 \%$ FBS before TGF- $\beta 1(10 \mathrm{ng} / \mathrm{ml})$ treatment for $24 \mathrm{~h}$. In the second series, cells were transfected with control shRNA, AAT1 shRNA or AAT2 shRNA for $24 \mathrm{~h}$. Then they were starved for $24 \mathrm{~h}$ followed by TGF- 31 treatment for $24 \mathrm{~h}$. In the third series, cells were transfected with control shRNA, AAT1 shRNA or AAT2 shRNA for $24 \mathrm{~h}$, staved for $24 \mathrm{~h}$, treated with SB431542 $(5 \mu \mathrm{mol} / \mathrm{L})$ for $1 \mathrm{~h}$, and then stimulated with TGF- $\beta 1 \mathrm{for} 24 \mathrm{~h}$.

The cells were fixed with $4 \%$ paraformaldehyde $(0.01 \mathrm{~mol} / \mathrm{L} \mathrm{PBS,} \mathrm{pH} 6.8)$, washed with PBS, incubated with rabbit anti-collagen I primary antibody (1:25; Sigma-Aldrich) and rabbit anti-collagen III primary antibody (1:25; Sigma-Aldrich) respectively at $4{ }^{\circ} \mathrm{C}$ overnight. Next day, after washing, the coverslips were incubated with secondary antibody (1:100) (Invitrogen, Carlsbad, CA) in the dark for $90 \mathrm{~min}$ at room temperature. The slides were viewed using a Fluoview laser scanning confocal microscope (Olympus, Tokyo, Japan). In the negative control group, IgG was used instead of the first antibody. 
Measurement of $\mathrm{SO}_{2}$ concentration in VSMCs supernatant by high-performance liquid chromatography with fluorescence detection. VSMCs supernatants were collected for $\mathrm{SO}_{2}$ content determination. $\mathrm{SO}_{2}$ concentrations were measured using high-performance liquid chromatography with fluorescence detection (HPLC-FD, Agilent 1200 series, Agilent Technologies, Palo Alto, CA, USA) ${ }^{9}$. Briefly, 100 $\mu$ L of VSMCs supernatant was mixed with $70 \mu \mathrm{L}$ of $0.212 \mathrm{M}$ sodium borohydride in $0.05 \mathrm{M}$ Tris- $\mathrm{HCl}(\mathrm{pH} 8.5)$ and incubated at $28^{\circ} \mathrm{C}$ for $30 \mathrm{~min}$. The sample was then mixed with $10 \mu \mathrm{L}$ of $70 \mathrm{mM} \mathrm{mBrB}$ in acetonitrile, incubated for $10 \mathrm{~min}$ at $42^{\circ} \mathrm{C}$, and then mixed with $40 \mu \mathrm{L}$ of $1.5 \mathrm{M}$ perchloric acid. Protein precipitate in the mixture was removed by centrifugation at $12400 \times \mathrm{g}$ for $10 \mathrm{~min}$ at $25^{\circ} \mathrm{C}$. The supernatant was immediately neutralized by adding $10 \mu \mathrm{L}$ of $2 \mathrm{M}$ Tris- $\mathrm{HCl}(\mathrm{pH} 3.0$ ), and centrifuged at $12400 \times \mathrm{g}$ for $10 \mathrm{~min}$. The neutralized supernatant was used for HPLC-FD. Sulfitebimane was measured by excitation at $392 \mathrm{~nm}$ and emission at $479 \mathrm{~nm}$. Quantification was carried out by the standardization of sodium sulfite.

Measurement of endogenous $\mathrm{SO}_{2}$ content in VSMCs by a fluorescent probe. Endogenous $\mathrm{SO}_{2}$ in VSMCs was measured using a fluorescent probe (kindly provided by Professor Kun Li, College of Chemistry, Sichuan University, Sichuan, China). The culture supernatant of VSMCs was discarded, and washed with PBS for three times. Then, the cells were stained in the working liquid of fluorescent probe $(10 \mu \mathrm{M})$ for $1 \mathrm{~h}$ at $37^{\circ} \mathrm{C}$, washed with PBS and then fixed with $4 \%$ paraformaldehyde for $15 \mathrm{~min}$ at room temperature. After washed with PBS, the cells were detected as blue fluorescent by confocal microscopy.

Phosphorylation of T $\beta$ RI in VSMCs evaluated by immunoprecipitation. VSMCs were seeded in $100-\mathrm{mm}$ dishes for immunoprecipitation. When cells were grown to $60-70 \%$ confluences, they were treated as follows. In the first series, cells were transfected with vehicle, AAT1 or AAT2 plasmid. After $24 \mathrm{~h}$, they were starved in DMEM with $0.5 \%$ FBS before TGF- $\beta 1(10 \mathrm{ng} / \mathrm{ml})$ treatment for $1 \mathrm{~h}$. In the second series, cells were transfected with control shRNA, AAT1 shRNA or AAT2 shRNA for $24 \mathrm{~h}$. Then they were starved for $24 \mathrm{~h}$ followed by TGF- $\beta 1$ treatment for $1 \mathrm{~h}$.

The cells were then harvested with the antibody against T $\beta$ RI (Santa Cruz Biotechnology, catalog sc-398) before immunoprecipitation with protein A/G agarose beads (Thermo Fisher Scientific, Waltham, MA, USA) ${ }^{20,36}$. The precipitated proteins were resolved by $10 \%$ SDS-PAGE and then immunoblotted with antibody against phosphoserine (Abcam, Cambridge, MA, USA) ${ }^{20}$.

Statistical analysis. Results are presented as mean \pm SD. Statistical comparisons were performed with PRISM5 software (GraphPad). Comparisons among more than 2 groups involved one-way ANOVA followed by the Student-Newman-Keuls test for post-hoc comparison as appropriate. $P<0.05$ was considered significant.

\section{References}

1. Rocnik, E. F., Chan, B. M. \& Pickering, J. G. Evidence for a role of collagen synthesis in arterial smooth muscle cell migration. J. Clin. Invest. 101, 1889-98 (1998).

2. Intengan, H. D. \& Schiffrin, E. L. Vascular remodeling in hypertension: roles of apoptosis, inflammation, and fibrosis. Hypertension. 38, 581-7 (2001).

3. Kim, H. J. et al. Peroxisome proliferator-activated receptor $\{$ delta\} regulates extracellular matrix and apoptosis of vascular smooth muscle cells through the activation of transforming growth factor-\{beta\}1/Smad3. Circ. Res. 105, 16-24 (2009).

4. Zhao, J. et al. Urotensin II-induced collagen synthesis in cultured smooth muscle cells from rat aortic media and a possible involvement of transforming growth factor- $\beta 1 / \mathrm{Smad} 2 / 3$ signaling pathway. Regul. Pept. 182, 53-8 (2013).

5. Zhao, X. et al. Regulatory effect of hydrogen sulfide on vascular collagen content in spontaneously hypertensive rats. Hypertens. Res. 31, 1619-30 (2008).

6. Yan, H., Du, J. \& Tang, C. The possible role of hydrogen sulfide on the pathogenesis of spontaneous hypertension in rats. Biochem. Biophys. Res. Commun. 313, 22-7 (2004).

7. Stipanuk, M. H. Metabolism of sulfur-containing amino acids. Annu. Rev. Nutr. 6, 179-209 (1986).

8. Shapiro, R. Genetic effects of bisulfite (sulfur dioxide). Mutat. Res. 39, 149-75 (1977).

9. Sun, Y. et al. Effects of sulfur dioxide on hypoxic pulmonary vascular structural remodeling. Lab. Invest. 90, 68-82 (2010).

10. Pardali, E., Goumans, M. J. \& ten Dijke, P. Signaling by members of the TGF-beta family in vascular morphogenesis and disease. Trends. Cell. Biol. 20, 556-67 (2010).

11. Border, W. A. \& Ruoslahti, E. Transforming growth factor-beta in disease: the dark side of tissue repair. J. Clin. Invest. 90, 1-7 (1992).

12. Massagué, J. Wounding Smad. Nat. Cell. Biol. 1, E117-9 (1999).

13. Li, W. et al. Tgfbr2 disruption in postnatal smooth muscle impairs aortic wall homeostasis. J. Clin. Invest. 124, 755-67 (2014).

14. Mullen, A. C. et al. Master transcription factors determine cell-type-specific responses to TGF- $\beta$ signaling. Cell. 147, 565-76 (2011).

15. Liu, D. et al. Sulfur dioxide inhibits vascular smooth muscle cell proliferation via suppressing the Erk/MAP kinase pathway mediated by cAMP/PKA signaling. Cell. Death. Dis. 5, e1251 (2014).

16. Sun, H. J. et al. Salusin- $\beta$ contributes to vascular remodeling associated with hypertension via promoting vascular smooth muscle cell proliferation and vascular fibrosis. Biochim. Biophys. Acta. 1852, 1709-1718 (2015).

17. Xu, J. \& Shi, G. P. Vascular wall extracellular matrix proteins and vascular diseases. Biochim. Biophys. Acta. 1842, 2106-2119 (2014).

18. Jacob, M. P. et al. Extracellular matrix remodeling in the vascular wall. Pathol. Biol (Paris). 49, 326-32 (2001).

19. Du, S. et al. Endogenously generated sulfur dioxide and its vasorelaxant effect in rats. Acta. Pharmacol. Sin. 29, 923-930 (2008).

20. Sun, L. et al. Hydrogen sulfide alleviates myocardial collagen remodeling in association with inhibition of TGF- $\beta /$ Smad signaling pathway in spontaneously hypertensive rats. Mol. Med. 20, 503-15 (2015).

21. Giannandrea, M. \& Parks, W. C. Diverse functions of matrix metalloproteinases during fibrosis. Dis. Model. Mech. 7, 193-203 (2014).

22. Mori, S. et al. Expression and Roles of MMP-2, MMP-9, MMP-13, TIMP-1, and TIMP-2 in Allergic Nasal Mucosa. Allergy. Asthma. Immunol. Res. 4, 231-9 (2012).

23. Cevik, C. et al. Rosuvastatin therapy does not affect serum MMP-13 or TIMP-1 levels in hypercholesterolemic patients. Tex. Heart. Inst. J. 38, 229-33 (2011).

24. Verrecchia, F. \& Mauviel, A. Transforming growth factor-beta signaling through the Smad pathway: role in extracellular matrix gene expression and regulation. J. Invest. Dermatol. 118, 211-5 (2002).

25. Ghosh, J. et al. The role of transforming growth factor betal in the vascular system. Cardiovasc. Pathol. 14, 28-36 (2005).

26. Lambers, C. et al. The interaction of endothelin-1 and TGF- 31 mediates vascular cell remodeling. PLoS One. 8, e73399 (2013). 
27. González-Ramos, M. et al. HSP70 increases extracellular matrix production by human vascular smooth muscle through TGF- $\beta 1$ up-regulation. Int. J. Biochem. Cell. Biol. 45, 232-242 (2013).

28. Stow, R. C., Mallawaarachchi, C. M. \& Weissberg, P. L. Migration of adventitia myofibroblasts following vascular balloon injury: insights from in vivo gene transfer to rat carotid arteries. Cardiovasc. Res. 59, 212-21 (2003).

29. Schiller, M., Javelaud, D. \& Mauviel, A. TGF-beta-induced SMAD signaling and gene regulation: consequences for extracellular matrix remodeling and wound healing. J. Dermatol. Sci. 35, 83-92 (2004).

30. Mauviel, A. Transforming growth factor-beta: a key mediator of fibrosis. Methods. Mol. Med. 117, 69-80 (2005).

31. Dai, X. et al. SMAD3 deficiency promotes vessel wall remodeling, collagen fiber reorganization and leukocyte infiltration in an inflammatory abdominal aortic aneurysm mouse model. Sci. Rep. 5, 10180 (2015).

32. Singer, T. P. \& Kearney, E. B. Intermediary metabolism of L-cysteinesulfinic acid in animal tissues. Arch Biochem Biophys. 61, 397-409 (1956)

33. Harvey, S. A. et al. Responses of cultured human keratocytes and myofibroblasts to ethyl pyruvate: a microarray analysis of gene expression. Invest Ophthalmol Vis Sci. 51, 2917-27 (2010).

34. Ju, K. D. et al. Ethyl pyruvate ameliorates albuminuria and glomerular injury in the animal model of diabetic nephropathy. Am J Physiol Renal Physiol. 302, F606-13 (2012).

35. Varma, S., Hegde, K. \& Kovtun, S. Oxidative damage to lens in culture: reversibility by pyruvate and ethyl pyruvate. Ophthalmologica. 220, 52-57 (2000).

36. Kang, S. H. et al. Transcriptional repression of the transforming growth factor-beta type I receptor gene by DNA methylation results in the development of TGF-beta resistance in human gastric cancer. Oncogene. 18, 7280-6 (1999).

\section{Acknowledgements}

We thank Dr Jia Liu for her assistances in cell culture and $\mathrm{SO}_{2}$ measurement. This work was supported by the National Natural Science Foundation of China (Grant Nos. 81400311, 31440052 and 91439110) and by the Major Basic Research Development Program of China (Nos. 2012CB517806 and 2013CB933801).

\section{Author Contributions}

Y.H. designed and executed most of the experiments and analyzed the results. Z.S. and Q.C. detected the $\mathrm{SO}_{2}$ concentration by HPLC-FD and analyzed the results. P.H. and H.Z. operated the confocal microscope, took pictures and analyzed the results. S.D., B.G. and C.Z. analyzed the data and interpretated the results. K.L. prepared the fluorescent probe of $\mathrm{SO}_{2}$ and executed the experiments. C.T., J.D. and H.J. designed the project, analyzed the data, interpretated the results and revised the manuscript. Y.H., J.D. and H.J. prepared the manuscript.

\section{Additional Information}

Competing financial interests: The authors declare no competing financial interests.

How to cite this article: Huang, Y. et al. Endogenous sulfur dioxide alleviates collagen remodeling via inhibiting TGF- $\beta /$ Smad pathway in vascular smooth muscle cells. Sci. Rep. 6, 19503; doi: 10.1038/srep19503 (2016).

(c) (i) This work is licensed under a Creative Commons Attribution 4.0 International License. The images or other third party material in this article are included in the article's Creative Commons license, unless indicated otherwise in the credit line; if the material is not included under the Creative Commons license, users will need to obtain permission from the license holder to reproduce the material. To view a copy of this license, visit http://creativecommons.org/licenses/by/4.0/ 